\title{
ONDAS DE FRIO INTENSAS SOBRE O NORDESTE DO ESTADO DE SÃO PAULO ENTRE 1961 a 2017
}

\author{
LUCYRIO, Vinícius - vinicius.lucyrio@gmail.com \\ Universidade Federal de Itajubá - UNIFEI \\ REBOITA, Michelle Simões - reboita@gmail.com \\ Universidade Federal de Itajubá - UNIFEI
}

\author{
ALBIERI, Marcelo de Campos Garcia - malbieri@unicamp.br \\ Universidade Estadual de Campinas - UNICAMP
}

\begin{abstract}
RESUMO: Este estudo teve como objetivo elaborar uma metodologia para identificação das ondas de frio (OF) mais intensas ocorridas no nordeste do Estado de São Paulo entre 1961 e 2017. Para tanto, foram usados dados de temperatura mínima e máxima medidos em 10 estações meteorológicas convencionais. O método de identificação das OF consistiu em compilar as informações das 10 séries temporais em apenas uma e na aplicação de um percentil muito restritivo, de $0,2 \%$, para seleção dos casos mais intensos de OF. Foram identificadas 12 OF intensas, com duração média de 5 dias. Todos os casos provocaram geada na região de estudo, que muitas vezes causaram perdas na agricultura. Para descrição do padrão sinótico da atmosfera associado com os casos de OF, foi realizada uma análise de composição (média de uma dada variável atmosférica em datas específicas). Em superfície, foi observado que a incursão de ar polar para latitudes mais baixas ocorre devido às características de circulação do Anticiclone Subtropical do Pacífico Sul (ASPS) e de uma baixa pressão no oceano Atlântico, que interagem favorecendo a advecção de ar frio. Em médios e altos níveis da atmosfera, observa-se um padrão de onda amplificado, com crista no Pacífico e cavado no Atlântico e América do Sul, que propicia o avanço do ar frio para o norte e dá suporte dinâmico ao centro de alta pressão migratório.
\end{abstract}

Palavras-chave: onda de frio, padrão sinótico, geada, São Paulo

INTENSE COLD WAVES OVER NORTH-CENTER OF THE STATE OF SÃO PAULO BETWEEN 1961 AND 2017

ABSTRACT: This study aims to elaborate a methodology for identification of the most intense cold waves occurred in the north-center of the State of São Paulo between 1961 and 2017. Therefore, minimum and maximum temperature data measured at 10 conventional meteorological stations were used. For the cold waves identification initially the 10 temporal series were compiled into just one, and a very restrictive percentile, of $0,2 \%$, for selecting the most intense cases of cold waves, were applied. 12 intense cold waves were identified, with 5 days of average duration. All cases caused frost in the study region, and the most impact negatively the agriculture. To describe the synoptic pattern of the the atmosphere associated with these cold waves, a composite analysis (average of a given atmospheric variable in specific dates) was performed. At surface, it was observed that the South Pacific Subtropical High and a low pressure area over Atlantic Ocean interact and contribute to cold air advection. In middle and high levels of atmosphere, it is observed an amplified wave pattern, with a ridge over Pacific and a trough over Atlantic and South America, that provides cold air advance to the north and gives dynamic support to the migratory high pressure center.

Keywords: cold wave, synoptic pattern, frost, São Paulo

\section{INTRODUÇÃO}

Uma onda de frio (OF) é definida pela Sociedade Americana de Meteorologia como sendo uma rápida queda na temperatura do ar dentro de 24 
horas, exigindo proteção à agricultura, indústria, comércio e atividades sociais (GLICKMAN, 2000). Já a Organização Meteorológica Mundial (OMM) define OF como um evento caracterizado pela forte queda nas temperaturas próximas à superfície (mínima, máxima e média diária) sobre uma grande área e persistindo abaixo de certos limiares por pelo menos dois dias consecutivos (WMO, 2016). Portanto, as OF podem ser caracterizadas como eventos meteorológicos extremos (WMO, 2016; IPCC, 2013) que causam impactos sociais e econômicos. O setor agrícola é um dos mais prejudicados por esses eventos, uma vez que as OF favorecem condições propícias a geadas e até mesmo neve em regiões mais elevadas (ALVES et al., 2017). O impacto das geadas varia de acordo com a espécie vegetal atingida (PINTO et al, 1976), mas sua repercussão econômica é maior quando atingem regiões de latitudes mais baixas (HAMILTON e TARIFA, 1978).

Para a América do Sul, há vários estudos que descrevem o padrão espacial das incursões de ar frio que caracterizam episódios de OF, entre eles: Titarelli (1972), Hamilton e Tarifa (1978), Fortune e Kousky (1983), Girardi (1983), Marengo et al. (1997), Krishnamurti et al. (1999), Garreaud (2000), Garreaud e Aceituno (2001), Lupo et al. (2001), Vera et al. (2002), Pezza (2003), Escobar et al. (2004), Pezza e Ambrizzi (2005), Escobar (2007), Espinoza et al. (2012), Mendonça e Romero (2012), Müller et al. (2015), Reboita et al. (2015), Ricarte et al. (2015), Lanfredi e Camargo (2018) Escobar et al. (2019) e Capucin et al. (2019). De acordo com esses autores, em geral, em superfície, há um centro de alta pressão transiente no oceano Pacífico que se move em direção ao extremo sul da América do Sul, se intensificando ao cruzar a Argentina e, nos 2 ou 3 dias seguintes, torna-se semi-estacionário entre o sul e sudeste do Brasil. Essa condição atmosférica pode ser propícia à ocorrência de geadas.

A região extratropical da América do Sul é a mais afetada com as OF do que a subtropical e tropical, já que esses sistemas perdem intensidade ao se deslocarem para menores latitudes. Entretanto, com base na literatura, desde 1961 há o registro de vários episódios de OF muito intensas que afetaram o Estado de São Paulo. Entre 1961 a 2000, Pezza (2003), ao realizar um levantamento bibliográfico, tomando como base os dados de temperaturas mínimas de Campinas e São Paulo (estação meteorológica do IAG/USP), identificou 33 eventos de frio que provocaram geadas, sendo que em 13 casos ocorreram danos significativos às plantações de café no referido Estado (Marengo et al., 1997), cujas datas de ocorrência foram 07/07/1962, 22/06/1963, 28/07/1964, 21/08/1965, 11/07/1969, 09/07/1972, 18/07/1975, 31/05/1979, 21/07/1981, 27/08/1984, 08/06/1985, 26/06/1994 e 09/07/1994.

Algumas das OF relatadas por Pezza (2003) foram estudadas por diferentes autores. Monteiro (1965) analisou a OF ocorrida entre 19 e 22 de agosto de 1965. O autor cita que o ar frio chegou a Manaus, além de ter provocado geadas que afetaram a produção agrícola nos municípios de Jales, São Carlos, Descalvado, Louveira, Campinas e Bauru. Essa mesma OF provocou neve em parte do Rio Grande do Sul, Santa Catarina e Paraná, com acúmulo de quase 1 metro em Palmas, PR; já em Campinas, SP, fez a temperatura mínima chegar a $0,6^{\circ} \mathrm{C}$ no dia 21 de agosto (PEZZA, 2003). Hamilton e Tarifa (1978) descreveram os aspectos sinóticos da OF ocorrida na segunda semana de julho de 1972, que atingiu a região tropical do Brasil. Cerca de metade dos pés de café no Paraná foram destruídos pelos ventos fortes associados ao ar polar, e 
muitas perdas também foram registradas nas plantações no Estado de São Paulo.

A OF de julho de 1975 é um dos eventos de OF da América do Sul mais estudados (PARMENTER, 1976; GIRARDI, 1983; MARENGO et al., 1997; e PEZZA, 2003), por ser considerado um dos eventos mais intensos do século XX (PEZZA, 2003). Durante essa OF uma alta pressão com núcleo de $1041 \mathrm{hPa}$ atingiu as latitudes de $25^{\circ} \mathrm{S}$ (PEZZA, 2003) e o ar frio ultrapassou a linha do Equador, chegando ao Hemisfério Norte (PARMENTER, 1976). Também foi através da análise dessa OF que Girardi (1983) introduziu o termo "Poço dos Andes". Girardi (1983), através de imagens de satélite, indicou que a ocorrência de OF na América do Sul é precedida pela existência de um sistema de alta pressão migratório na costa do Chile. Como nas imagens de satélite as regiões de alta pressão possuem tons escuros, o autor denominou essa característica de "Poço dos Andes". Essa OF de 1975 causou geadas no sul e sudeste do Brasil e neve em Foz do Iguaçu e Curitiba. De acordo com Marengo et al. (1997), houve uma queda de $51 \%$ na produção de café em virtude desse evento, com perdas de 75 milhões de dólares em danos.

Fortune e Kousky (1983) realizaram a análise do padrão sinótico de dois casos de geadas ocorridos em regiões tropicais do Brasil, um em maio de 1979 e outro em julho de 1981, que tiveram como precursores a incursão de ar frio polar. Em ambos os eventos, o ar frio ultrapassou a linha do Equador e ocorreram geadas em São Paulo e Minas Gerais; no caso de 1981, também foi registrada a ocorrência de geadas no estado do Mato Grosso do Sul. Camargo (1997) menciona que este evento foi extremamente severo, com grandes prejuízos nas plantações de café no sudeste do Brasil (PEZZA, 2003). Com relação à OF de junho de 1985, esta causou neve na Serra da Mantiqueira (PEZZA, 2003), especialmente no Parque Nacional de Itatiaia, com grande acúmulo no Pico das Agulhas Negras, e danos aos cafezais provocados pela geada, fatos que sugerem a ocorrência de uma OF muito intensa no sudeste do Brasil. Outro caso de OF intenso no Estado de São Paulo foi o de agosto de 1987, conforme mencionado por Escobar (2007).

Marengo et al. (1997) e Krishnamurti et al. (1999) destacam os impactos da OF de junho de 1994 na cafeicultura e descrevem a trajetória sinótica dos sistemas associados, com um anticiclone migratório semi-estacionário entre o sul e sudeste do Brasil, atuando em conjunto com um ciclone extratropical próximo das Ilhas Malvinas. Alguns dias após o máximo declínio das temperaturas no sudeste do Brasil, houve grande aumento no preço do café. Ainda no mesmo ano, mas entre 9 e 11 de julho, outra OF afetou o Estado de São Paulo conforme Pezza (2003). Considerando a OF de julho de 2000, segundo Lanfredi e Camargo (2018) essa foi a mais intensa em 17 anos e uma das mais importantes em 100 anos. Neste evento, foi registrada temperatura de $-0,2^{\circ} \mathrm{C}$ na cidade de São Paulo, com significativo impacto econômico (MARENGO et al., 2002).

Embora existam diferentes metodologias para a identificação de OF (ALVES et al., 2017), o presente estudo tem como objetivo apresentar uma metodologia simples para a identificação de OF intensas (que causam queda acentuada de temperatura do ar podendo gerar um ambiente propício a geadas) durante o período frio no nordeste do Estado de São Paulo (maio a agosto) entre 1961 e 2017. Portanto, esse trabalho traz como contribuições: uma metodologia simples que pode ser adaptada para qualquer área de interesse, 
atualiza o estudo de Pezza (2003) e ainda apresenta uma análise de composição dos eventos identificados. Destaca-se, também, que a metodologia apresentada é validada com base nos casos documentados por Pezza (2003).

\section{METODOLOGIA}

\subsection{DADOS}

Para a realização desse estudo, foram utilizados dados de temperatura mínima (Tmin) e máxima (Tmax), no período de 1961 a 2017, de 10 estações meteorológicas (Tabela 1 e Figura 1) localizadas no nordeste do Estado de São Paulo e Triângulo Mineiro. As estações meteorológicas são pertencentes ao Instituto Agronômico de Campinas (IAC) e ao Instituto Nacional de Meteorologia (INMET). A partir das temperaturas mínimas e máximas foi obtida a temperatura média diária (Tmed), sendo calculada como Tmed $=($ Tmax + Tmin $) / 2$.
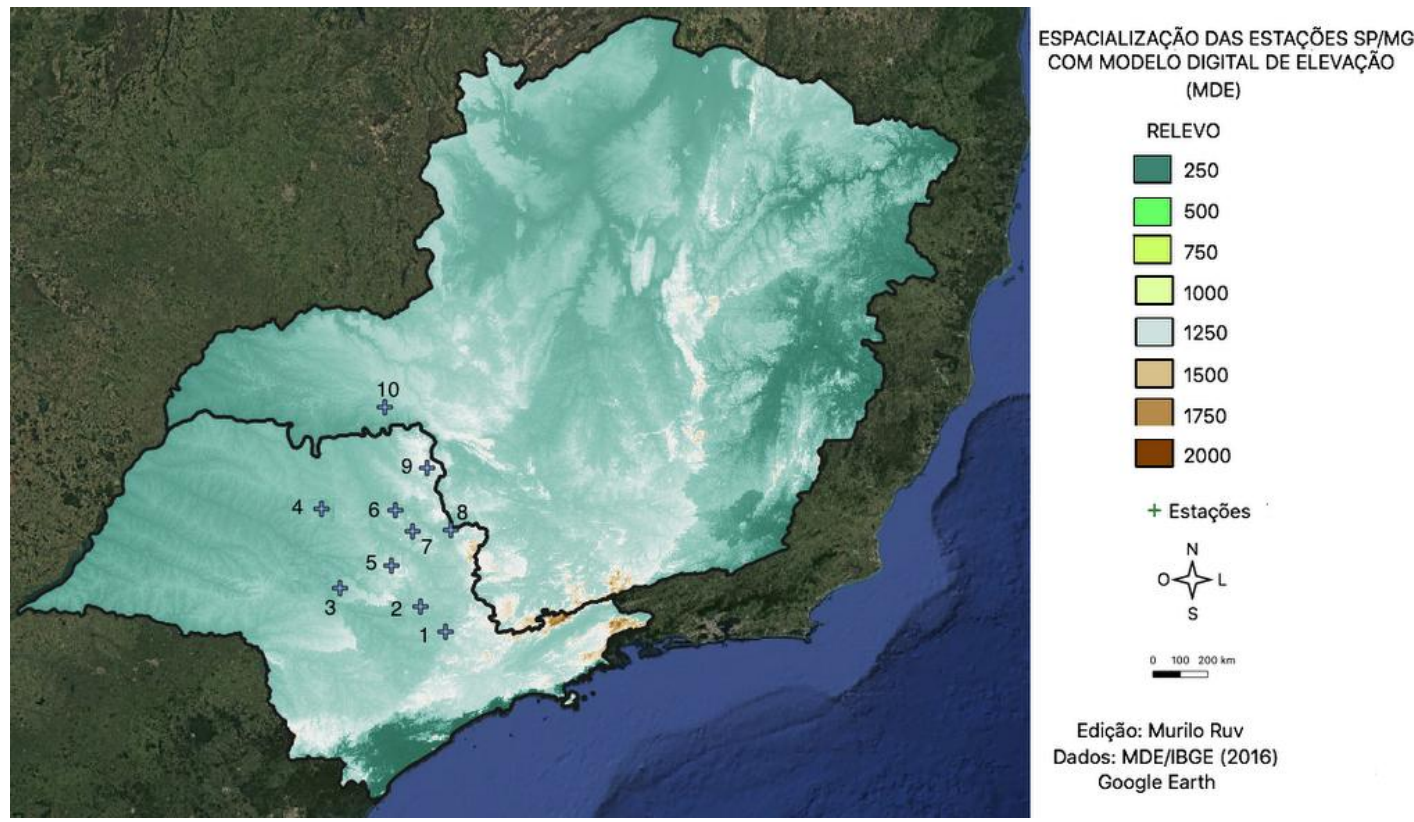

Figura 1 - Mapa topográfico de São Paulo e Minas Gerais. Os pontos indicam a localização das estações meteorológicas utilizadas no estudo, conforme descrição na Tabela 1.

Conforme documentado por Pezza (2003), a maioria das OF que afetam o Estado de São Paulo ocorrem durante o período frio. Portanto, o presente estudo se restringe aos meses de maio a agosto, em que são encontradas as menores temperaturas sobre a região nordeste do Estado de São Paulo conforme mostra a Figura 2.

Antes da aplicação da metodologia para identificação das OF, os dados passaram por um controle de qualidade, a fim de desconsiderar valores inconsistentes (REBOITA et al., 2018). Esse controle de qualidade envolveu primeiramente identificar a presença de dados errôneos, ou seja, valores que a temperatura do ar não poderia assumir como, por exemplo, temperaturas de $50^{\circ} \mathrm{C}$. O próximo passo foi verificar se as temperaturas registradas nas estações 
meteorológicas de estudo eram coerentes entre essas estações. A Tabela 1, além das informações geográficas das estações meteorológicas, apresenta a porcentagem de dados desconsiderados para o estudo em cada série temporal. Destaca-se aqui que foram encontradas inconsistências em vários dados da estação meteorológica convencional de São Carlos (OMM 83726) a partir de 2010. Então, os dados do período de 2010 a 2017 foram substituídos pelos registros da estação automática, situada no mesmo local da convencional.

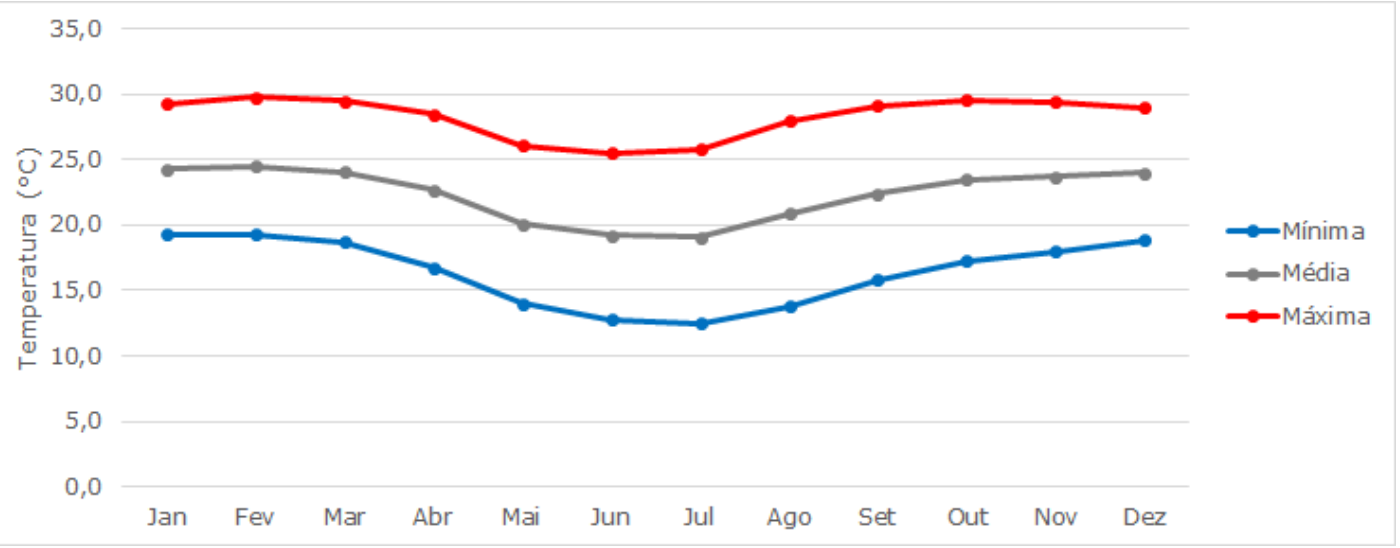

Figura 2 - Ciclo anual das temperaturas mínima, média e máxima no nordeste do Estado de São Paulo no período de 1961 a 2017. As médias das temperaturas foram calculadas considerando as 10 estações meteorológicas descritas na Tabela 1.

Tabela 1 -Estações meteorológicas utilizadas no estudo. IAC indica Instituto Agronômico de Campinas e INMET indica Instituto Nacional de Meteorologia.

\begin{tabular}{|c|c|c|c|c|c|c|c|c|}
\hline No & Estação & Instituto & $\begin{array}{l}\text { Código } \\
\text { OMM }\end{array}$ & $\begin{array}{l}\text { Altitude } \\
\text { (metros) }\end{array}$ & Lat. & Lon. & $\begin{array}{l}\text { Período } \\
\text { de dados }\end{array}$ & $\begin{array}{c}\% \text { de } \\
\text { dados } \\
\text { omitidos }\end{array}$ \\
\hline 1 & Campinas & IAC & 83729 & 669 & $-22,88^{\circ}$ & $-47,10^{\circ}$ & $1961-2017$ & $0,00 \%$ \\
\hline 2 & Limeira & IAC & 83728 & 639 & $-22,53^{\circ}$ & $-47,45^{\circ}$ & $1961-2017$ & $<0,01 \%$ \\
\hline 3 & Jaú & IAC & 83723 & 580 & $-22,28^{\circ}$ & $-48,57^{\circ}$ & $1961-2010$ & $<0,01 \%$ \\
\hline 4 & Catanduva & INMET & 83676 & 570 & $-21,11^{\circ}$ & $-48,93^{\circ}$ & $1961-2017$ & $10,67 \%$ \\
\hline 5 & São Carlos & INMET & 83726 & 856 & $-21,96^{\circ}$ & $-47,86^{\circ}$ & $1961-2017$ & $5,62 \%$ \\
\hline 6 & Rib. Preto & IAC & 83668 & 621 & $-21,18^{\circ}$ & $-47,80^{\circ}$ & $1961-2017$ & $<0,01 \%$ \\
\hline 7 & São Simão & INMET & 83669 & 617 & $-21,48^{\circ}$ & $-47,55^{\circ}$ & $1961-2017$ & $15,60 \%$ \\
\hline 8 & Mococa & IAC & 83680 & 665 & $-21,46^{\circ}$ & $-47,02^{\circ}$ & $1961-2017$ & $<0,01 \%$ \\
\hline 9 & Franca & INMET & 83630 & 1026 & $-20,58^{\circ}$ & $-47,36^{\circ}$ & $1961-2017$ & $4,31 \%$ \\
\hline 10 & Uberaba & INMET & 83577 & 737 & $-19,73^{\circ}$ & $-47,95^{\circ}$ & $1961-2017$ & $16,29 \%$ \\
\hline
\end{tabular}

\subsection{DESCRIÇÃO DA METODOLOGIA PARA DETECÇÃO DE ONDAS DE FRIO}

A maioria das metodologias para a identificação de OF utiliza a série temporal de temperatura (mínima, média ou máxima) de um dado local e seleciona os eventos que apresentam temperatura abaixo de um determinado limiar ou valor de temperatura por uma sequência de dias (FIRPO et al., 2012; LANDA, 2012; CUNHA e LEAL, 2013; NAIRN e FAWCETT, 2013; MATEUS, 2014; REBOITA et al., 2015; SILVEIRA, 2016; YAGUE et al., 2016; VAVRUS et al., 2016; ALVES et al., 2017). Um dos diferenciais do método descrito neste trabalho é que ele compila a informação de várias séries temporais, que forem disponíveis numa determinada região, numa única série temporal para a detecção apenas dos casos mais intensos de OF, muitas vezes com potencial para geadas que afetam a produção agrícola na região estudada. 
O método utilizado aqui envolve basicamente três etapas: redução da informação espacial (de várias estações meteorológicas) numa única série temporal, identificação dos eventos de OF e definição da duração das OF. A primeira etapa consiste em:

E1.1) calcular a média da Tmin, Tmax e Tmed de cada estação meteorológica para todo o período de estudo (assim, os valores obtidos podem ser considerados como climatológicos em cada estação meteorológica);

E1.2) computar as anomalias diárias de Tmin, Tmax e Tmed, também de cada estação. As anomalias são obtidas através da diferença entre o dado diário e a média calculada em (E1.1);

E1.3) para cada dia do período em estudo, calcula-se a média das anomalias obtidas nas estações meteorológicas (no caso, aqui são 10 estações). Portanto, esse passo reduz a informação de várias séries temporais numa única por variável, tornando a metodologia robusta e simples. Ressalta-se aqui que essa metodologia é adequada para estudos regionais.

A etapa da identificação das OF envolve a técnica de percentis e a variável Tmin. Antes da utilização do percentil que será mostrado, foram realizados testes iniciais, com base em casos de OF intensas descritos na literatura (PEZZA, 2003), para a definição de um valor apropriado para seleção das OF intensas e obteve-se o valor de 0,2\%. Assim, as etapas da identificação das OF intensas são:

E2.1) a partir da série temporal das médias das anomalias de Tmin obtidas em E1.3 calcula-se o percentil de $0,2 \%(P 0,2)$. Nesse cálculo é obtido o valor da anomalia de Tmin que corresponde a tal percentil e que será usado como um limiar. Livros de estatística básica como, por exemplo, Triola (2017) mostram o cálculo dos percentis;

E2.2) identificar na série temporal das médias das anomalias de Tmin (E1.3) os dias em que a anomalia foi menor ou igual a do P0,2. Assim, encontram-se somente os dias em que ocorreram OF muito fortes;

E2.3) com a utilização do critério descrito, em geral, não se obtém uma sequência de dias consecutivos frios, caracterizando a duração da OF. Se apenas um determinado dia é obtido, esse é considerado o dia pico (d0); se mais de um dia for obtido, considera-se aquele com a anomalia mais fria como sendo do.

Para definir a duração dos eventos de OF, é levada em consideração a série temporal de anomalias diárias da Tmed. O motivo para a utilização da Tmed e não da Tmin é que quando uma massa de ar frio adentra uma região, mesmo que ela comece a perder intensidade, o céu pode ainda permanecer sem nebulosidade o que causa grande perda radiativa noturna e implicando em Tmin muito baixa. Por outro lado, durante o dia a Tmax consegue se elevar. Portanto, a Tmed considera esses dois efeitos e não mascara a informação de que ainda prevaleça a OF intensa (Ynoue et al., 2017). Os passos para a obtenção da duração das OF são:

E3.1) calcula-se, a partir da série temporal das médias de Tmed, a diferença $(\Delta T)$ da Tmed de um dado dia (Td0) em relação à Tmed do dia anterior (Td-1);

E3.2) o início de uma OF é o primeiro dia antes de do (dia pico) com $\Delta \mathrm{T}<0$ e o fim é o segundo dia consecutivo com $\Delta \mathrm{T}>0$ após d0; 
E3.3) entretanto, se durante o período detectado houver dias com anomalia de Tmed $\geq 0$, esses serão desconsiderados da duração da OF. A razão para essa restrição é que, em geral, anomalias positivas de Tmed indicam a presença de massas de ar tropicais dominando na região, e não de ar polar.

Para facilitar a compreensão da metodologia descrita, é fornecido o exemplo a seguir para o caso de uma OF ocorrida entre os dias 25 e 29 de junho de 1994. A Tabela 2 mostra as temperaturas (Tmin, Tmed e Tmax), considerando a média diária de todas as estações meteorológicas do estudo, bem como suas anomalias e também a diferença da Tmed em relação ao dia anterior, desde 2 dias antes do início até 2 dias após o fim da OF. O dia pico (d0) foi definido como o dia 27 de junho de 1994 pois a anomalia de Tmin ($12,7^{\circ} \mathrm{C}$ ) ficou abaixo do limiar do $\mathrm{P0}, 2$, que foi de $-10,82^{\circ} \mathrm{C}$ (Tabela 2). A duração da OF foi definida como sendo o primeiro dia com $\Delta T<0$ antes de 27 de junho de 1994, que foi 25 de junho de 1994, até o segundo dia com $\Delta T>0$ após 27 de junho, ou seja, 29 de junho. Portanto, essa OF teve duração de 5 dias.

Tabela 2 - Exemplo de OF identificada pelo método descrito, ocorrida entre 25 e 29 de junho de 1994. As temperaturas apresentadas nas colunas Tmin, Tmax e Tmed correspondem as médias das estações meteorológicas utilizadas.

\begin{tabular}{ccccccccc}
\hline Data & $\begin{array}{c}\text { Tmin } \\
\left({ }^{\circ} \mathbf{C}\right)\end{array}$ & $\begin{array}{c}\text { Tmax } \\
\left({ }^{\circ} \mathbf{C}\right)\end{array}$ & $\begin{array}{c}\text { Tmed } \\
\left({ }^{\circ} \mathbf{C}\right)\end{array}$ & $\begin{array}{c}\text { Anom. } \\
\text { Tmin }\end{array}$ & $\begin{array}{c}\text { Anom. } \\
\text { Tmax }\end{array}$ & $\begin{array}{c}\text { Anom. } \\
\text { Tmed }\end{array}$ & $\begin{array}{c}\text { Diferença } \\
\text { Tmed } \\
(\Delta \mathbf{\Delta})\end{array}$ & Observações \\
\hline $\mathbf{2 3 / 0 6 / 1 9 9 4}$ & 14,0 & 22,7 & 18,3 & 0,6 & $-3,6$ & $-1,5$ & 0,4 & \\
$\mathbf{2 4 / 0 6 / 1 9 9 4}$ & 12,7 & 27,1 & 19,9 & $-0,7$ & 0,9 & 0,1 & 1,6 & Início da OF \\
$\mathbf{2 5 / 0 6 / 1 9 9 4}$ & 10,9 & 19,0 & 14,9 & $-2,5$ & $-7,3$ & $-4,9$ & $-5,0$ & \\
$\mathbf{2 6 / 0 6 / 1 9 9 4}$ & 1,7 & 14,9 & 8,3 & $-11,7$ & $-11,3$ & $-11,5$ & $-6,6$ & Dia pico (d0) \\
$\mathbf{2 7 / 0 6 / 1 9 9 4}$ & 0,6 & 20,7 & 10,7 & $-12,7$ & $-5,5$ & $-9,1$ & 2,4 & \\
$\mathbf{2 8 / 0 6 / 1 9 9 4}$ & 3,5 & 23,3 & 13,4 & $-9,9$ & $-2,9$ & $-6,4$ & 2,7 & Fim da OF \\
$\mathbf{2 9 / 0 6 / 1 9 9 4}$ & 6,1 & 24,9 & 15,5 & $-7,3$ & $-1,4$ & $-4,3$ & 2,1 & \\
$\mathbf{3 0 / 0 6 / 1 9 9 4}$ & 11,1 & 27,2 & 19,2 & $-2,2$ & 0,9 & $-0,6$ & 3,7 & \\
$\mathbf{0 1 / 0 7 / 1 9 9 4}$ & 12,6 & 27,7 & 20,1 & $-0,8$ & 1,5 & 0,3 & 1,0 & \\
\hline
\end{tabular}

\subsection{ANÁLISE DE COMPOSIÇÃO}

Uma vez identificadas as ocorrências de OF, foram determinadas composições das variáveis atmosféricas pressão ao nível médio do mar (PNMM), espessura da camada entre 1000 e 500 hPa (EC), vento em $250 \mathrm{hPa}$ (V250), água precipitável (PWAT), anomalia da temperatura em $2 \mathrm{~m}$ (T2M), temperatura (T850) e direção do vento no nível de $850 \mathrm{hPa}$ (V850), obtidas da reanálise ERA20-C (POLI et al., 2016). As composições correspondem à média de uma dada variável considerando o dia pico (d0), isto é, a média dos campos atmosféricos no horário das $12 Z$ do dia pico. Além disso, as composições também foram determinadas para os 4 dias anteriores e 3 dias posteriores ao d0. A reanálise ERA-20C é disponível desde 1900 até 2018 e possui resolução horizontal de $125 \mathrm{~km}$. A resolução é grosseira pois o interesse é na análise dos padrões de maior escala, e não nos padrões regionais. As composições permitirão descrever o padrão sinótico da atmosfera quando da ocorrência de OF na região de estudo. 


\section{RESULTADOS}

\subsection{EVENTOS IDENTIFICADOS DE OF}

Com a metodologia descrita, foram identificadas 12 OF, sendo 4 episódios em junho, 5 em julho e 3 em agosto. Os casos detectados são mostrados na Tabela 3, com suas datas de início e fim, além da anomalia de Tmin no dia pico (d0) e ocorrências de geada documentadas na literatura. A Figura 3 mostra que o ano de 1994 teve maior frequência de OF intensas, com 2 ocorrências. Nota-se que há diferença entre o número registrado aqui e os de Pezza (2003), pois o autor utilizou outra metodologia para identificar as OF (Tmin igual ou menor que $2,5^{\circ} \mathrm{C}$ na estação meteorológica de Campinas) e se restringiu a uma localidade mais a sul da área que o presente estudo aborda.

Tabela 3 - Ondas de frio identificadas após a aplicação da metodologia descrita, com as datas de início, pico e fim, além da anomalia do dia pico ( $(\mathrm{d} 0)$, em ${ }^{\circ} \mathrm{C}$, a duração em dias e ocorrências de geada documentadas na literatura.

\begin{tabular}{|c|c|c|c|c|c|}
\hline Início & Pico (d0) & Fim & Duração & $\begin{array}{l}\text { Anomalia de } \\
\text { Tmin (d0) }\end{array}$ & $\begin{array}{c}\text { Ocorrência de } \\
\text { geadas }\end{array}$ \\
\hline 20/08/1965 & $21 / 08 / 1965$ & 23/08/1965 & 4 & $-12,9$ & $\begin{array}{c}\text { Monteiro (1965); Pezza } \\
\text { (2003) }\end{array}$ \\
\hline 08/07/1972 & 09/07/1972 & $11 / 07 / 1972$ & 4 & $-10,9$ & $\begin{array}{c}\text { Hamilton e Tarifa } \\
\text { (1978) }\end{array}$ \\
\hline $17 / 07 / 1975$ & $18 / 07 / 1975$ & 20/07/1975 & 4 & $-12,4$ & $\begin{array}{c}\text { Parmenter (1976); } \\
\text { Girardi (1983); } \\
\text { Marengo et al. (1997); } \\
\text { Pezza (2003) }\end{array}$ \\
\hline $13 / 08 / 1978$ & $15 / 08 / 1978$ & $17 / 08 / 1978$ & 5 & $-11,5$ & \\
\hline $30 / 05 / 1979$ & $01 / 06 / 1979$ & 03/06/1979 & 5 & $-12,7$ & $\begin{array}{c}\text { Fortune e Kousky } \\
\text { (1983); Pezza (2003) }\end{array}$ \\
\hline $18 / 07 / 1981$ & $21 / 07 / 1981$ & 23/07/1981 & 6 & $-13,7$ & $\begin{array}{c}\text { Fortune (1982); } \\
\text { Fortune e Kousky } \\
\text { (1983); Camargo } \\
\text { (1997); Pezza (2003) }\end{array}$ \\
\hline 03/06/1985 & $08 / 06 / 1985$ & $10 / 06 / 1985$ & 9 & $-11,5$ & \\
\hline 06/08/1987 & $08 / 08 / 1987$ & $10 / 08 / 1987$ & 5 & $-10,8$ & \\
\hline 04/06/1988 & $05 / 06 / 1988$ & 07/06/1988 & 4 & $-11,2$ & \\
\hline 25/06/1994 & $27 / 06 / 1994$ & 29/06/1994 & 5 & $-12,7$ & $\begin{array}{c}\text { Marengo et al. (1997); } \\
\text { Krishnamurti et al. } \\
\text { (1999); Pezza (2003) }\end{array}$ \\
\hline 08/07/1994 & $10 / 07 / 1994$ & $12 / 07 / 1994$ & 5 & $-12,5$ & \\
\hline $16 / 07 / 2000$ & $17 / 07 / 2000$ & $19 / 07 / 2000$ & 4 & $-11,9$ & $\begin{array}{c}\text { Lanfredi e Camargo } \\
(2018)\end{array}$ \\
\hline
\end{tabular}

Em geral, as OF têm duração média de 5 dias. Nos eventos detectados, 10 eventos tiveram 4 ou 5 dias de duração, enquanto apenas 2 tiveram mais do que 5 dias; destaca-se a OF ocorrida em junho de 1985, com 9 dias de duração. Considerando-se todos os casos, foi calculada a média das anomalias de Tmin, Tmax e Tmed, além do $\Delta \mathrm{T}$, desde 3 dias antes do dia pico ( $\mathrm{d}-3$ ) até 3 dias após $(d+3)$ para obter um caso geral, que é mostrado na Tabela 4. 


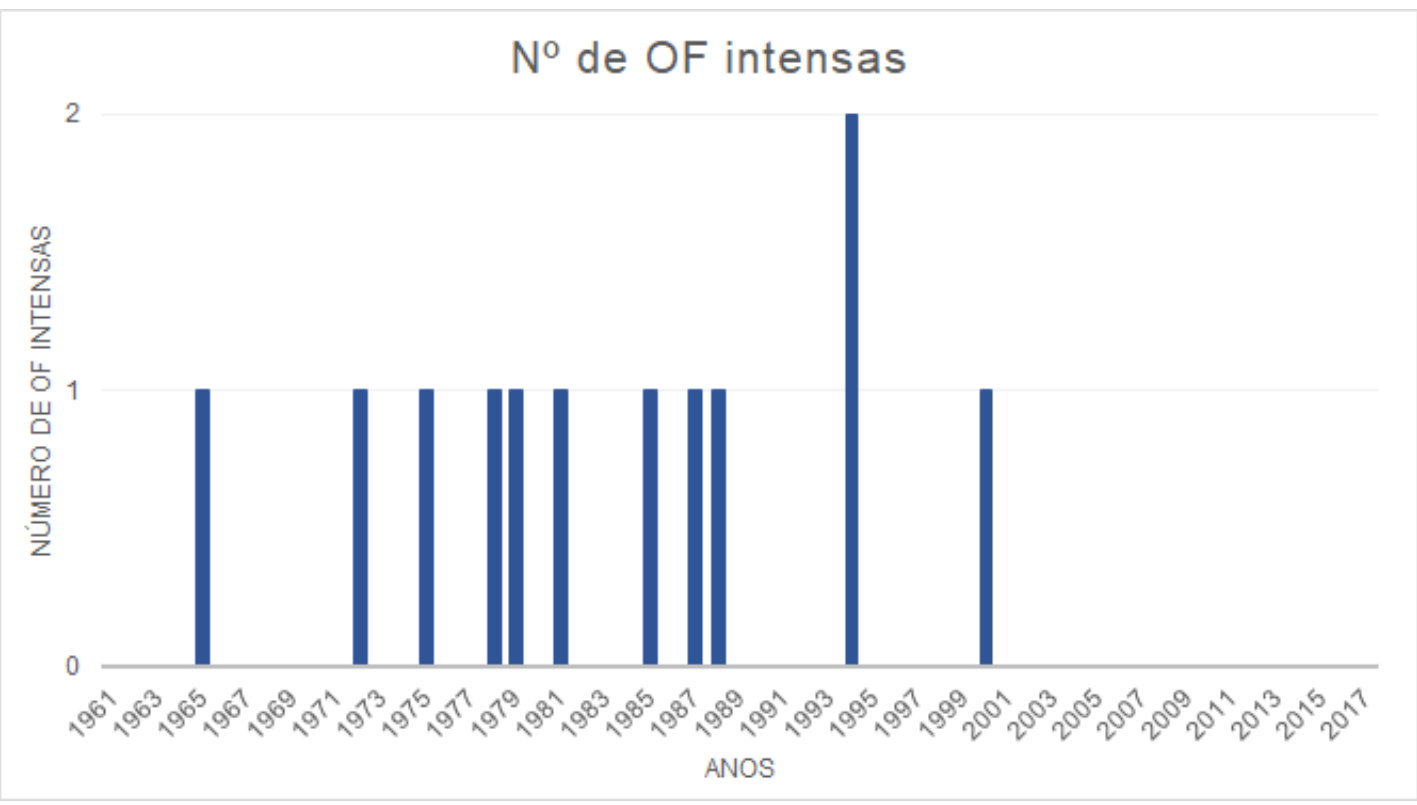

Figura 3 - Número de OF intensas por ano, de 1961 a 2017.

Tabela 4 - Caso geral de OF intensa obtido através das médias das anomalias de Tmin, Tmax e Tmed $\left({ }^{\circ} \mathrm{C}\right)$, além do $\Delta \mathrm{T}$, de $\mathrm{d}-2 \mathrm{a} \mathrm{d}+2$. A tabela mostra as médias de $\mathrm{d}-3 \mathrm{a} \mathrm{d}+3$.

\begin{tabular}{cccccc}
\hline Dia & Tmin & Tmed & Tmax & $\mathbf{\Delta T}$ & Observações \\
\hline d-3 & $-0,4$ & $-0,3$ & $-0,3$ & 0,5 & \\
d-2 & $-1,3$ & $-2,1$ & $-2,9$ & $-1,8$ & Iní́cio da OF \\
d-1 & $-7,1$ & $-8,5$ & $-9,8$ & $-6,4$ & \\
d0 & $-12,1$ & $-10,6$ & $-9,1$ & $-2,1$ & Dia pico (d0) \\
d+1 & $-9,1$ & $-7,1$ & $-5,0$ & 3,5 & \\
d+2 & $-5,3$ & $-3,8$ & $-2,3$ & 3,4 & Fim da OF \\
d+3 & $-2,6$ & $-1,7$ & $-0,8$ & 1,9 & \\
\hline
\end{tabular}

A maior queda nas temperaturas é observada de $d-2$ para $d-1$, com uma média de $-6,4^{\circ} \mathrm{C}$. Em d0, a diminuição na temperatura em relação a $\mathrm{d}-1$ é menos acentuada, ao passo que em $d+1$ e $d+2$ já se percebe um notável aumento, denotando enfraquecimento do ar polar.

A Tabela 3 mostra os casos de OF com geadas descritas na literatura. Os eventos ocorridos em agosto de 1978, junho de 1985, agosto de 1987, junho de 1988 e julho de 1994 não possuem menção de ocorrência de geadas na região nordeste do estado de São Paulo, bem como seus impactos sociais e econômicos, na literatura científica. Por outro lado, artigos da mídia impressa descrevem a ocorrência de geadas nas datas citadas. Além disso, os dados meteorológicos usados para a detecção das OF também podem ser usados como proxy para a ocorrência desses eventos. Camargo et al. (1993) considerou $2^{\circ} \mathrm{C}$ ou menos de temperatura no abrigo meteorológico como limiar para prejuízos com geada. Isto em função de se conhecer que em noites de tempo estável, sem vento e nebulosidade, a temperatura da relva, isto é, próxima ao solo, pode ser bem menor que a temperatura medida no abrigo meteorológico, sendo comum a observação de diferenças de 4 a $5^{\circ} \mathrm{C}$ entre 0 abrigo e a relva (BOOTSMA, 1980; PINTO et al., 1978; SENTELHAS et al., 1995).

A OF ocorrida entre 13 e 17 de agosto de 1978, com pico no dia 15 (anomalia de $\operatorname{Tmin}$ no pico em $-11,5^{\circ} \mathrm{C}$ ), causou prejuízos em cerca de $25 \%$ nos 
cafezais do Paraná e São Paulo, e pelo menos $20 \%$ do trigo no Paraná. Em São Paulo, além do café, sofreram danos as plantações de feijão, amendoim, tomate e milho. Na região agrícola de Araraquara, café e cana-de-açúcar foram as culturas que mais sofreram com os efeitos da OF (O Estado de São Paulo, $16 / 08 / 1978$, p.38). No dia 15 de agosto, a temperatura mínima foi de $-1,3^{\circ} \mathrm{C}$ em Jaú, $0,7^{\circ} \mathrm{C}$ em Catanduva e $1,4^{\circ} \mathrm{C}$ em Franca, e no dia 16 fez $0,0^{\circ} \mathrm{C}$ em São Simão.

Nos dias 9 e 10 de junho de 1985, as regiões de São José do Rio Preto, Ribeirão Preto, Catanduva e Franca também foram atingidas por geadas, segundo informações do jornal O Estado de São Paulo (11/06/1985, p.14). Em Ribeirão Preto, a geada foi mais intensa e ampla em regiões de baixada, mesmo assim causou danos nas plantações de feijão e café. Em Franca e Batatais, entre 30 e $40 \%$ dos cafezais foram atingidos. A região de Catanduva e Pindorama teve prejuízos na fruticultura e na olivicultura. A geada afetou seriamente as pastagens em grande parte do estado de São Paulo, o que prejudicou a produção de leite na região de Bragança Paulista. A duração deste evento de OF, além de sua intensidade, chama a atenção, pois foram 9 dias com temperaturas baixas. Em Ribeirão Preto, fez $0,2^{\circ} \mathrm{C}$ no dia $8,0,3^{\circ} \mathrm{C}$ no dia 9 e $0,8^{\circ} \mathrm{C}$ no dia 10 . Em Franca, $1,8^{\circ} \mathrm{C}, 1,3^{\circ} \mathrm{C}$ e $1,4^{\circ} \mathrm{C}$ nos dias 8,9 e 10 respectivamente.

Em 1987, a OF ocorrida entre os dias 6 e 10 de agosto, com pico no dia 8, provocou temperaturas que chegaram a $1,0^{\circ} \mathrm{C}$ em Limeira, $1,4^{\circ} \mathrm{C}$ em São Simão, $2,2^{\circ} \mathrm{C}$ em Jaú e $2,6^{\circ} \mathrm{C}$ em Ribeirão Preto, valores compatíveis com a ocorrência de geadas menos severas. Na região de Franca, a geada afetou as plantações de café (O Estado de São Paulo, 09/08/1987, p. 38). Em Curitiba-PR, ocorreu precipitação de neve durante alguns minutos na tarde do dia 7 (O Estado de São Paulo, 08/08/1987, p.14).

Entre os dias 4 e 7 de junho de 1988, a OF com pico no dia 5 causou temperaturas de $1,0^{\circ} \mathrm{C}$ em Limeira, $1,3^{\circ} \mathrm{C}$ em Ribeirão Preto e São Carlos, $1,6^{\circ} \mathrm{C}$ em São Simão e $1,8^{\circ} \mathrm{C}$ em Campinas. As geadas foram fortes no norte do Paraná, e no interior de São Paulo causou problemas na região de Franca, onde a geada foi forte nas baixadas, São José do Rio Preto, com danos nas pastagens e plantações de hortaliças, e regiões de Casa Branca e Tambaú, onde as plantações de feijão foram afetadas (O Estado de São Paulo, 07/06/1988, p. 36).

No dia 10 de julho de 1994, temperaturas muito baixas foram registradas no nordeste do Estado de São Paulo: $-1,0^{\circ} \mathrm{C}$ em Limeira, $0,0^{\circ} \mathrm{C}$ em Mococa, $0,4^{\circ} \mathrm{C}$ em Ribeirão Preto e $0,6^{\circ} \mathrm{C}$ em Jaú. No Triângulo Mineiro, Uberaba registrou $-2,0^{\circ} \mathrm{C}$. As lavouras de café foram fortemente afetadas no norte do Estado de São Paulo e sul de Minas Gerais, onde houve perdas de até $80 \%$ (O Estado de São Paulo, 13/07/1994, p. G20; 27/07/1994, p.70). As geadas atingiram todas as regiões do Estado, e prejudicaram também lavouras de trigo, feijão, batata, tomate, mandioca, hortaliças e frutas tropicais em desenvolvimento (O Estado de São Paulo, 13/07/1994, p. G20).

\subsection{COMPOSIÇÕES}

A fim de descrever o padrão sinótico dos episódios de OF intensas que atingem o nordeste do Estado de São Paulo são apresentadas as composições dos casos identificados desde 4 dias antes do d0 até 3 dias após. 
Quatro dias antes de d0, é observada em superfície o ASPS (Anticiclone Subtropical do Pacífico Sul) próximo ao litoral do Chile e centrado entre as latitudes $25-35^{\circ} \mathrm{S}$ e as longitudes $80-90^{\circ} \mathrm{O}$; o ASAS (Anticiclone Subtropical do Atlântico Sul) estabelecido sobre o oceano Atlântico com ação direta sobre o sudeste do Brasil com posição central em $20-30^{\circ} \mathrm{S}$ e $10-20^{\circ} \mathrm{O}$; e uma área extensa de baixa pressão ao sul do Atlântico (sul de $40^{\circ} \mathrm{S}$ ), a leste das Ilhas Malvinas (Figura 4A). Outra área de baixa pressão é registrada no interior do continente, entre a Bolívia e o Paraguai. As isolinhas de EC denotam uma crista em 500 hPa sobre o Pacífico, quase empilhada ao ASPS, enquanto há uma um cavado suave sobre o sul da América do Sul. Este padrão ondulatório é observado de forma mais clara em altos níveis ( $250 \mathrm{hPa}$ ), com uma crista acima do ASPS e um cavado no sul do continente sul-americano (Figura 4A). Em 850 $\mathrm{hPa}$, é verificada circulação com ventos de noroeste em todo o sudeste e sul do Brasil, além do Mato Grosso do Sul, com convergência do escoamento de sudoeste entre o Uruguai e o centro da Argentina (Figura 4A). Há valores mais altos de PWAT a oeste do centro-oeste do Brasil e Bolívia, o que aponta transporte de ar mais quente e úmido para o centro-sul do Brasil. Com relação às temperaturas, há avanço de ar frio pelo interior do continente, entre o centro da Argentina e o sul da Amazônia, condizentes com os padrões verificados em médios e altos níveis (Figura $5 \mathrm{~A}$ ), e com as anomalias de T2M entre -5 e $-3^{\circ} \mathrm{C}$ na região especificada (Figura 6A). Em São Paulo e Minas Gerais, as temperaturas permanecem próximas da normalidade.

\section{$D-3$}

Em D-3, verifica-se uma alta migratória entrando no continente sulamericano como uma extensão do ASPS. Ao mesmo tempo, se observa amplificação do padrão de onda tanto em médios quanto em altos níveis, com orientação mais meridional; uma crista no Pacífico, empilhada no ASPS, e um cavado na América do Sul acompanhando o deslocamento da alta migratória (Figura 4B). Em altos níveis, é notável o acoplamento do Jato Subtropical (JS) com o ramo norte do Jato Polar (JPN), e sua intensidade (>48 m/s) demonstra intenso gradiente horizontal de temperatura em baixos níveis da atmosfera. A área de baixa pressão sobre o Atlântico Sul permanece a oeste das Ilhas Malvinas, centrada entre $40-50^{\circ} \mathrm{S}$ e $35-45^{\circ} \mathrm{O}$, e a baixa alongada sobre 0 continente é observada entre o Mato Grosso, Mato Grosso do Sul, oeste de São Paulo e norte do Paraná. É observada também convergência do V850 entre o sudoeste do Mato Grosso e leste do Paraná e Santa Catarina, com direção predominante de noroeste para sudeste; na mesma região, verifica-se aumento da quantidade de umidade entre o sul da Amazônia e o sudeste do Brasil, inclusive em São Paulo, que se observa pelos valores de PWAT (Figura 5B). São verificadas anomalias mais negativas de T2M desde o Rio Grande do Sul, passando pelo oeste de Santa Catarina e Paraná, Mato Grosso do Sul, até o Acre e sul do Amazonas, devido ao avanço do ar mais frio. Em São Paulo, observamse anomalias ligeiramente negativas de T2M, com visível gradiente entre o oeste e leste do estado. Há um aumento da T2M entre D-4 e D-3, explicado pelo ingresso de ar mais quente transportado pelos fluxos de noroeste (Figura 6B). 


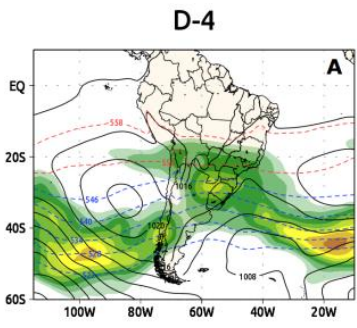

D0

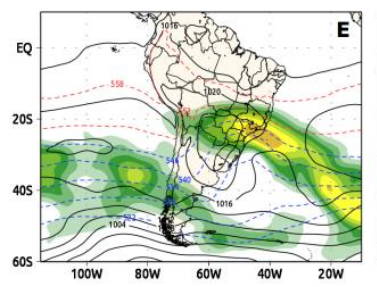

D-3

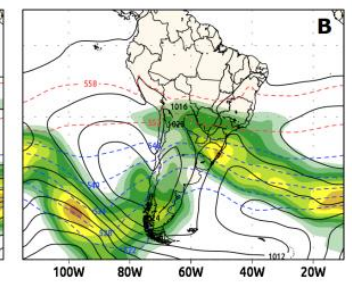

$\mathrm{D}+1$

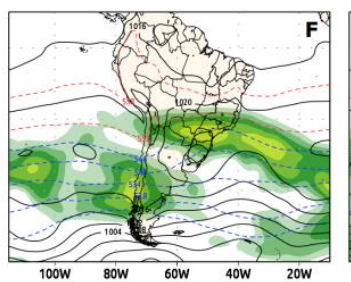

D-2

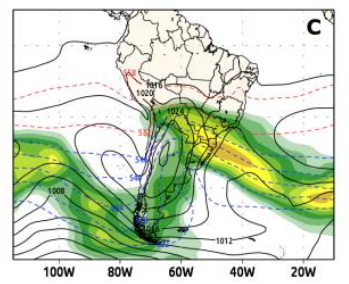

$D+2$

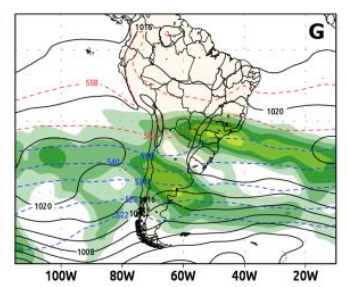

D-1

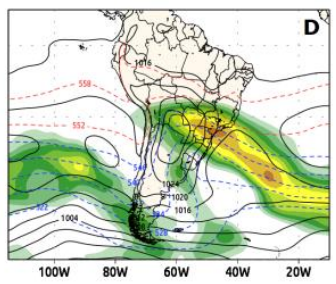

$\mathrm{D}+3$

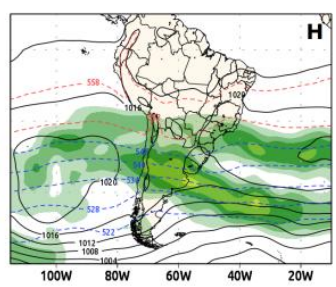

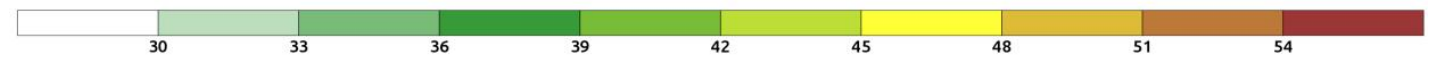

Figura 4 - Composições de Pressão ao Nível Médio do Mar (PNMM), vento em $250 \mathrm{hPa}$ (V250) com realce para valores acima de $30 \mathrm{~m} / \mathrm{s}$, e espessura da camada entre $1000 \mathrm{e}$ $500 \mathrm{hPa}$ em decâmetros, de d-4 a d+3.

\section{$D-2$}

Em superfície, é verificada uma intensificação da alta transiente sobre a Argentina, com PNMM no núcleo acima dos $1032 \mathrm{hPa}$, e bordas ao norte atingindo o Mato Grosso do Sul e sudoeste do Mato Grosso; observa-se também que o ASPS está atuando no litoral do Chile, entre $35-45^{\circ} \mathrm{S}$ e $70-90^{\circ} \mathrm{O}$; o padrão verificado em D-3 e D-2, com o ASPS no litoral do Chile e uma alta migratória sobre o continente sul-americano, é descrito por Girardi (1983) como "Poço dos Andes", e está associado ao ingresso de ar muito frio na América do Sul. Garreaud (2000) citou um padrão semelhante, com o movimento da alta migratória para o sul da Argentina em torno de $40^{\circ} \mathrm{S}$, onde a altitude na Cordilheira dos Andes não supera 2000 metros, seu avanço para o norte com e a amplificação de um cavado em baixos níveis da parte central do continente até o Atlântico Sul. A área de baixa pressão, que em D-3 se encontrava a oeste das Ilhas Malvinas, apresenta deslocamento de sudoeste para nordeste, e em D-2 está centrada entre $30-40^{\circ} \mathrm{S}$ e $35-45^{\circ} \mathrm{W}$, acompanhando o movimento do cavado em médios níveis, que está com orientação meridional, bem aprofundado e interiorizado, com atuação até o sul da Bolívia (Figura 4C). A circulação anticiclônica no Pacífico e a ciclônica no Atlântico, observadas desde D-4, favorecem a canalização do ar frio para o interior do continente. Em altos níveis, o JPN tem intensidade entre 48 e $51 \mathrm{~m} / \mathrm{s}$ no V250, entre o sul do Mato Grosso do Sul e região sul do Brasil. Observa-se um cavado em médios e altos níveis, que transporta ar muito frio para as regiões em seu interior, e dá suporte dinâmico para a intensificação da alta pressão em superfície. Em $850 \mathrm{hPa}$, ainda há convergência dos ventos sobre o sudeste do Brasil e aporte de umidade verificado por valores maiores de PWAT sobretudo no litoral norte de São Paulo 
e sul do Rio de Janeiro. Entre o sul de Rondônia, sudoeste do Mato Grosso, Mato Grosso do Sul e praticamente toda a região sul, os fluxos são de sul e sudoeste, com ingresso de ar mais seco sobre o oeste da região sul. A T850 encontra-se abaixo de $0^{\circ} \mathrm{C}$ na mesma região onde ingressou ar seco, com valores mais baixos que em D-3 sendo verificados em todo o interior do continente, entre 0 oeste do Paraná e sul de Rondônia (Figura 5C). Neste dia, as anomalias de T2M anotam valores entre $-9^{\circ} \mathrm{C}$ e $-5^{\circ} \mathrm{C}$ em grandes áreas sobre o Rio Grande do Sul, Santa Catarina, Paraná, oeste de São Paulo, Mato Grosso do Sul (onde as anomalias mais negativas são observadas), sul e oeste do Mato Grosso, Rondônia, Acre e sul do Amazonas (Figura 6C).

Total de Coluna de Agua (kg m-2), Temperatura $\left({ }^{\circ} \mathrm{C}\right)$ e Vento em $850 \mathrm{hPa}$ (Linhas de Corrente)
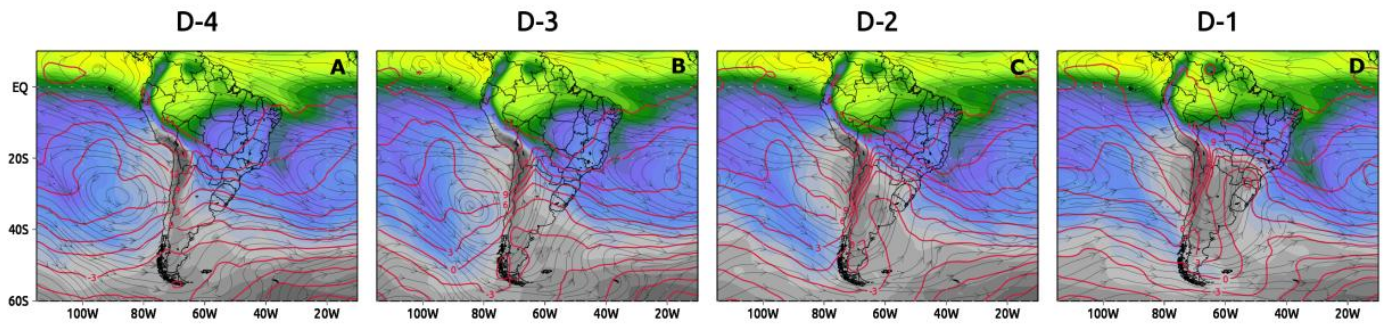

D0

$\mathrm{D}+1$

$D+2$

$\mathrm{D}+3$
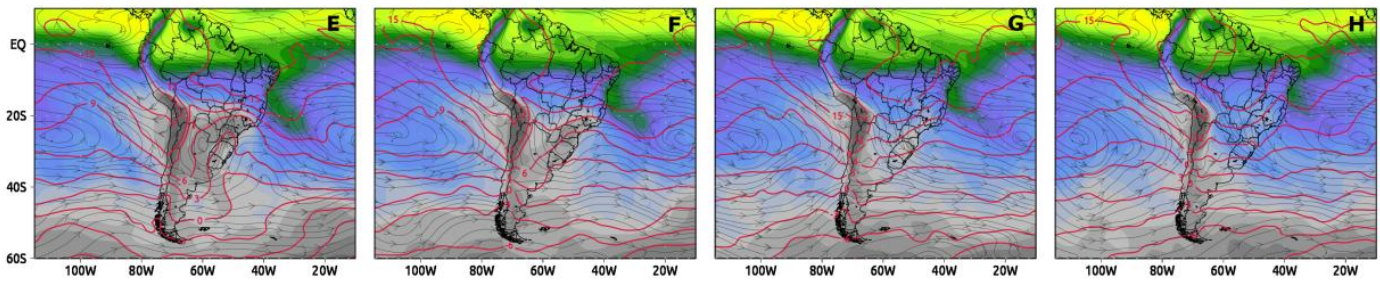

Figura 5 - Composições de água precipitável (PWAT), em $\mathrm{kg} \mathrm{m}-2$, isolinhas de temperatura em $850 \mathrm{hPa}$ (T850), e linhas de corrente do vento em $850 \mathrm{hPa}$ (V850).

$D-1$

Um dia antes de D0, é verificado o deslocamento máximo da alta transiente para o norte, que é ampla e se estabelece entre o centro-norte da Argentina, Paraguai e sul da Bolívia, passando pelo Mato Grosso do Sul, com bordas agindo em todo o sul do Brasil, centro-oeste de São Paulo, sudoeste de Goiás e sul do Mato Grosso, com núcleo acima dos $1028 \mathrm{hPa}$ centrado no Paraguai (Figura 4D). A área de baixa pressão no Atlântico segue seu deslocamento para norte-nordeste, verificado em D-2, e em D-1 nota-se o máximo gradiente de pressão no leste da região sul do Brasil. O JPN passa sobre o Rio Grande do Sul, Santa Catarina, Paraná e sul de São Paulo, com a máxima intensidade verificada (V250 entre 48 e 54 m/s em São Paulo, região com maior gradiente térmico horizontal em D-1). Em médios níveis, também é verificada a máxima intensidade e amplitude do cavado com orientação meridional sobre o sul do Brasil, São Paulo e Mato Grosso do Sul, enquanto entre o Chile e sul da Argentina percebe-se a amplificação de uma crista, que também é verificada em $250 \mathrm{hPa}$. O ASPS encontra-se desconfigurado neste dia. Em relação à umidade, nota-se ingresso de ar muito seco em todo o centro e oeste da região sul do 
Brasil, até o centro-sul do Mato Grosso do Sul e todo o sudoeste de São Paulo, com fluxos de sul-sudoeste do V850 (Figura 5D). A isoterma de $0^{\circ} \mathrm{C}$ em $850 \mathrm{hPa}$ estende-se pelo sul do Brasil, exceto a leste de Santa Catarina e Paraná, e pelo sul do Mato Grosso do Sul, com valores abaixo dos $10^{\circ} \mathrm{C}$ até o sudoeste do Mato Grosso, sul de Goiás, oeste e sul de Minas Gerais. Em São Paulo, valores abaixo dos $3^{\circ} \mathrm{C}$ são verificados em todo o sudoeste do estado. Nas anomalias de T2M, verificam-se temperaturas muito baixas em todo o sul, grande parte de São Paulo, sul e oeste de Minas Gerais, centro-sul de Goiás, todo o Mato Grosso (exceto extremo nordeste), extremo sudoeste do Pará, Rondônia, Acre e sul do Amazonas (Figura 6D). Na região de estudo, no dia D-1 é quando são verificadas as menores temperaturas máximas (Tabela 4), além do maior decréscimo da T2M.

D-4

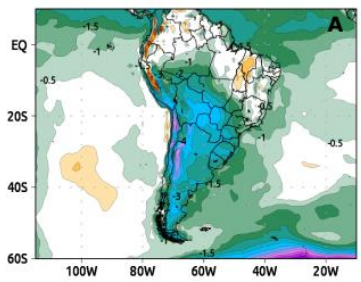

D0

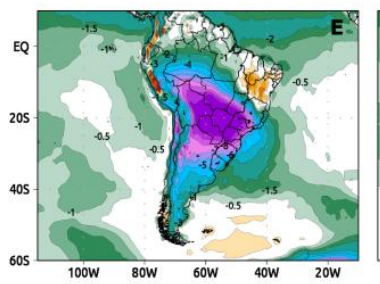

D-3

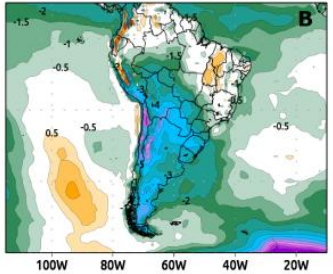

$\mathrm{D}+1$

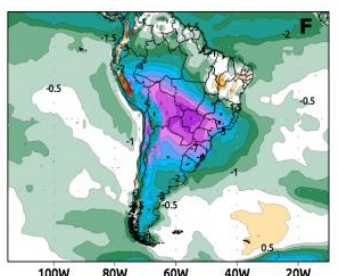

D-2

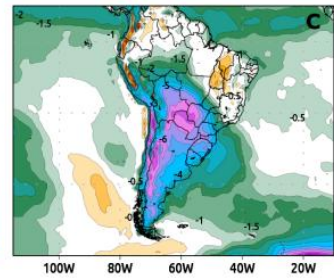

$D+2$

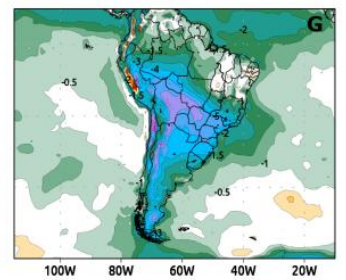

D-1

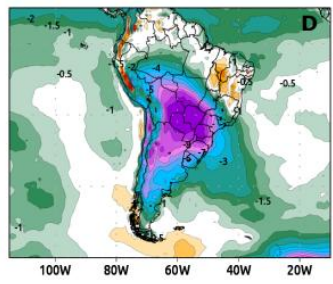

$D+3$

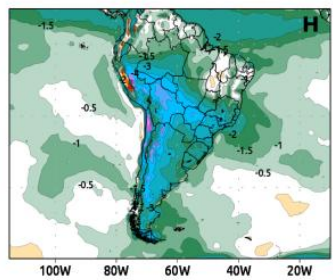

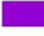

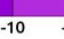

Figura 6 - Composições das anomalias de temperatura em 2m (T2M).

DO

Em D0, a alta transiente encontra-se estabelecida entre o oeste da região sul do Brasil, Paraguai, Mato Grosso do Sul e centro-oeste de São Paulo, propiciando condições de grande estabilidade na maior parte desta área. Sartori (2003) descreve as características atmosféricas associadas ao predomínio da alta: ventos fracos de sul, queda nas temperaturas mínimas e máximas, céu limpo e forte perda radiativa no período noturno, o que ocasiona a formação de orvalho, nevoeiros e geada. O gradiente de pressão ainda está presente ao longo do litoral das regiões sul e sudeste do Brasil devido à presença da área de baixa pressão com centro em torno de $30^{\circ} \mathrm{S}$ e $40^{\circ} \mathrm{O}$ (Figura 4E). O JPN ainda está presente com maior intensidade sobre o sul de São Paulo e litoral do Rio de Janeiro, e há enfraquecimento do cavado em médios níveis em seu deslocamento de oeste para leste. A presença de ar seco é relevante em grande parte do centro-sul do Brasil, e há um leve aumento na T850 em toda a região. O V850 ainda predomina no quadrante sul-sudoeste no sul e sudeste do Brasil (Figura 5E). Neste dia, as anomalias negativas de T2M associadas ao ingresso 
do ar frio se aproximam da linha do Equador, no Amazonas, e valores mínimos são observados em todo o Mato Grosso do Sul, Paraná, Santa Catarina, sul e oeste do Mato Grosso, sul de Goiás, oeste de Minas Gerais e grande parte de São Paulo (Figura 6E). A associação da estabilidade trazida pelo estabelecimento do anticiclone transiente, pouco vapor d'água disponível na atmosfera, temperaturas muito baixas, ausência de nebulosidade, além da ausência ou da baixa intensidade do vento devido à proximidade do núcleo da alta, propicia a ocorrência de geadas (GEIGER, 1965) em amplas áreas no sul, Mato Grosso do Sul, sul de Goiás, oeste e sul de Minas Gerais e São Paulo. Tanto em superfície quanto em médios e altos níveis, o padrão da composição apresentada é similar ao padrão EP (east penetration) descrito por Lanfredi e de Camargo (2018), que classificam OF extremas na América do Sul.

$D+1$

Um dia após D0, verifica-se que a alta transiente se estabelece sobre o sul do Brasil e perde intensidade, ao mesmo tempo em que a área de baixa pressão no Atlântico perde força e se afasta do continente (Figura 4F). Em médios níveis, ocorre enfraquecimento do cavado, sendo observado o mesmo com a corrente de jato em altos níveis, sem a presença do JPN, que é verificado agora entre o sul do Chile e da Argentina. As temperaturas começam a se elevar em todo o centro-sul do Brasil, exceto no Amazonas, onde o ar frio tem seu alcance máximo para o norte (Figura $6 \mathrm{~F}$ ). $\mathrm{Em} 850 \mathrm{hPa}$, as temperaturas também apresentam aumento gradual, com ventos de norte-nordeste (Figura $5 F)$. Ainda predominam condições de estabilidade que propiciam a ocorrência de geadas em especial no norte de São Paulo, sul e oeste de Minas Gerais e centroleste da região sul, devido à presença de ar muito seco (Figura 5F) que permite intensa perda radiativa durante a noite.

$D+2$ e $D+3$

Condições similares ocorrem 2 e 3 dias após o pico da OF, com a alta transiente perdendo força e aos poucos se deslocando para leste, até se agregar ao ASAS; no Pacífico, verifica-se a reconfiguração do ASPS (Figuras 4G e 4H). Com a presença crescente de V850 de quadrante norte-noroeste e aumento gradual das temperaturas tanto em $2 \mathrm{~m}$ quanto em $850 \mathrm{hPa}$ (Figuras 5G, 5H, 6G e $6 \mathrm{H})$, as temperaturas voltam a se elevar.

\subsection{ESTUDO DE CASO}

Nesta seção, são apresentados 2 casos típicos de OF na América do Sul, ocorridos entre 5 e 10 de junho de 2012, e entre 25 e 29 de junho de 1994 . O evento ocorrido em 2012 não afetou a área de estudo, já o de 1994 provocou sérios danos à agricultura em São Paulo (MARENGO et al., 1997; KRISHNAMURTI et al., 1999). Portanto, o objetivo aqui é descrever a diferença entre ambos. As figuras 7 e 8 mostram a evolução diária, às 12Z, da PNMM, V250 e EC dos casos de 1994 e 2012 respectivamente, e as figuras 9 e 10 mostram a T2M e as isolinhas de T850, de D-3 a D+2.

A OF de junho de 2012 atuou de forma mais restrita, afetando apenas o Rio Grande do Sul, Santa Catarina, sudoeste do Paraná e sul do Mato Grosso do Sul, e com menor intensidade no centro do Paraná, sudoeste do Mato Grosso, Rondônia, Acre e sudoeste de São Paulo. A OF de junho de 1994 teve uma atuação muito mais ampla, com rápido avanço da alta migratória pelo interior 
do continente e com núcleo mais ao norte em D-2 e D-1 (Figura 7B e 7C). As maiores diferenças são observadas na transposição da alta pelos Andes, que ocorre mais ao norte no caso de 1994 (Figura 7A). É observada também uma configuração mais favorável ao ingresso de ar mais frio para a América do Sul em 1994, com o ASPS posicionado mais a norte canalizando o ar polar com uma baixa pressão fechada no litoral da província de Buenos Aires (Figura 7A); o avanço do ar frio foi muito rápido, com a isoterma de $0^{\circ} \mathrm{C}$ da $\mathrm{T} 850$, que em $\mathrm{D}-3$ estava ao sul do Rio Grande do Sul, já no sudoeste do Mato Grosso do Sul em D-2 (Figuras 9A e 9B). Em D-1, o ar frio já estava no norte de Goiás e Mato Grosso, além de ter avançado para o sul do Amazonas e do Pará (Figura 9C).

Vento $250 \mathrm{hpa}>30 \mathrm{~m} / \mathrm{s}$, PNMM (hPa) e Espessura 1000/500 (dam)

D-3 24/06/94 12z

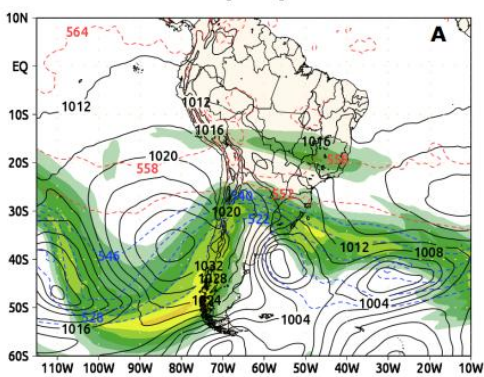

D0 $27 / 06 / 9412 z$
D-2 25/06/94 12z

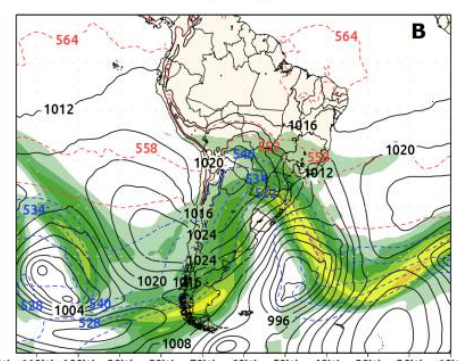

D+1 28/06/94 $12 z$
D-1 26/06/94 $12 z$

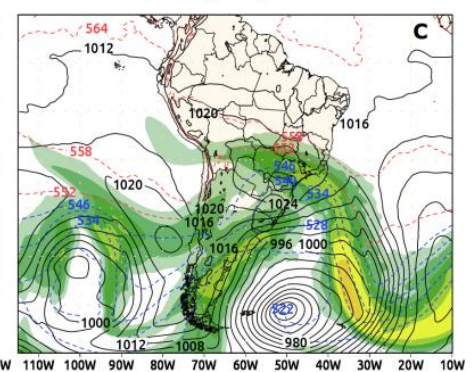

$D+2 \quad 29 / 06 / 9412 z$

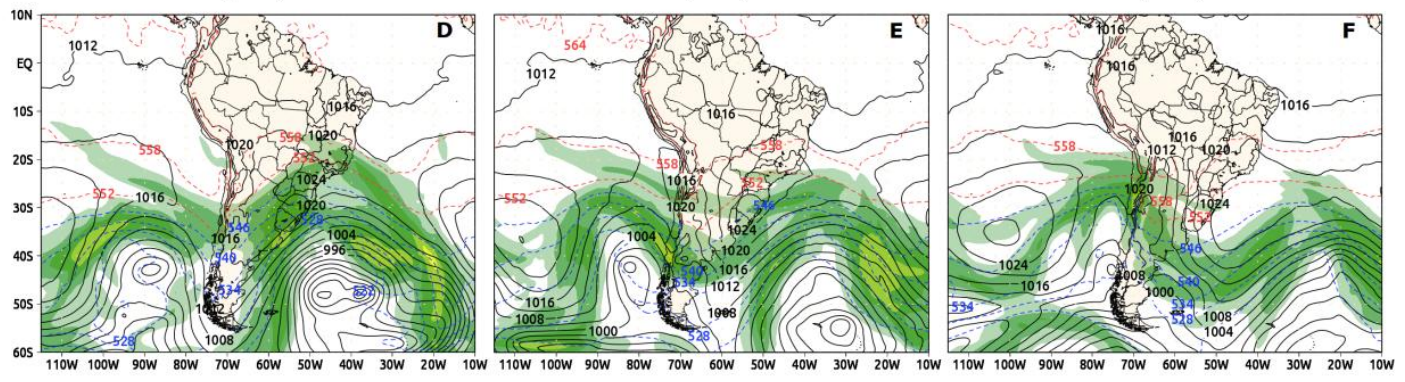

Figura 7 - Cartas de PNMM, V250 e EC de D-3 a D+2 da OF ocorrida entre os dias 25 e 29 de junho de 1994.

Em 2012, este ingresso ocorre com o ASPS a sul da posição verificada em 1994, com uma área de baixa pressão no sul do Atlântico, o que permitia uma atuação mais restrita do ar frio (Figura $8 \mathrm{~A}$ e $8 \mathrm{~B}$ ); a isoterma de $5^{\circ} \mathrm{C}$ em 850 hPa não avançou além de Santa Catarina (Figuras 10B, 10C, 10D e 10E). O núcleo da alta migratória é observado entre o oeste de São Paulo e o Paraná em D-1, no caso de 1994 (Figura 7C), sendo que em 2012 seu núcleo está posicionado ao sul do Paraguai (Figura $8 \mathrm{C}$ ). A posição da baixa pressão no Atlântico sul apresenta diferenças em D-1: no caso de 2012, o núcleo da baixa fechada é verificado quase a $60^{\circ} \mathrm{S}$, com maior gradiente de pressão observado entre o litoral sul da Argentina e o Uruguai (Figura 8C), enquanto em 1994 há um intenso ciclone extratropical a leste das Ilhas Malvinas, com intenso gradiente de pressão sendo registrado até o litoral de Santa Catarina (Figura 7C). Em D0, o anticiclone migratório tem núcleo mais ao sul no caso de 2012, com centro no oeste do Rio Grande do Sul e Uruguai (Figura 8D), ao passo que no evento de 1994 o núcleo de alta pressão estava atuando entre o Paraná e 
São Paulo (Figura 7D). A progressão do anticiclone em $D+1$ e $D+2$ é similar tanto no caso de 1994 quanto no de 2012, com sua trajetória para leste e consequente tropicalização (Figuras 7E, 7F, 8E e 8F) e enfraquecimento do ar frio (Figuras 9E, 9F, 10E e 10F).

Vento $250 \mathrm{hpa}>30 \mathrm{~m} / \mathrm{s}$, PNMM (hPa) e Espessura 1000/500 (dam)

D-3 $05 / 06 / 1212 z$

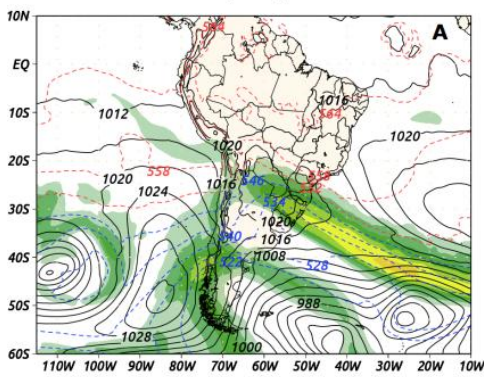

Do $08 / 06 / 1212 z$
D-2 06/06/12 12z

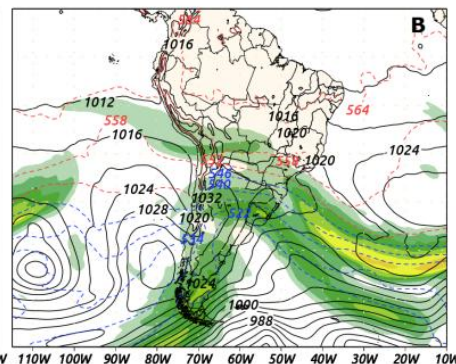

D+1 $09 / 06 / 1212 z$
D-1 07/06/12 $12 z$

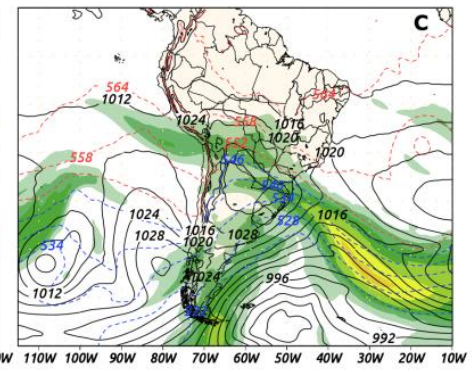

D+2 10/06/12 $12 z$

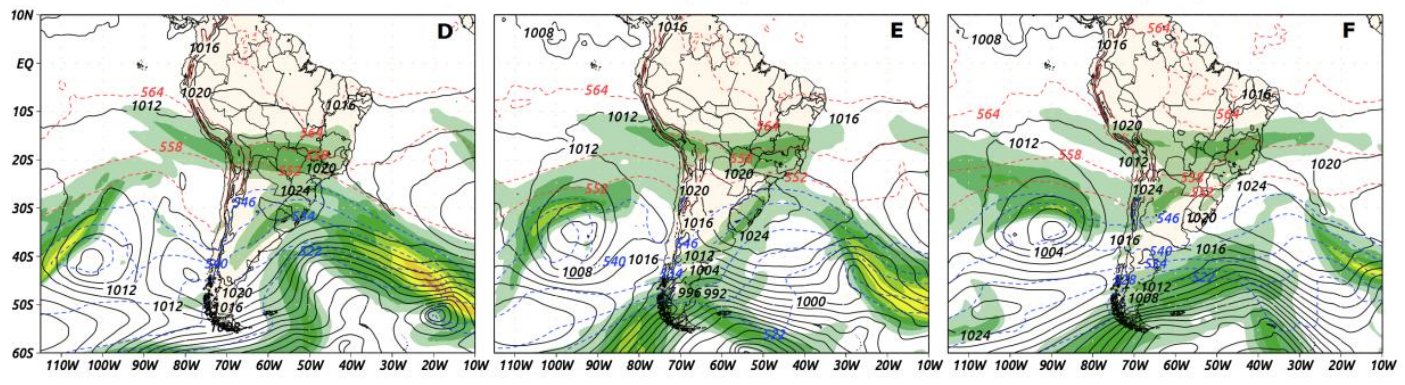

30

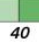

60

80

90

100

Figura 8 - Cartas de PNMM, V250 e EC de D-3 a D+2 da OF ocorrida entre os dias 5 e 10 de junho de 2012.

Em médios e altos níveis, as diferenças são mais marcantes. A evolução do cavado em níveis superiores e a posição do JPN são determinantes para o suporte dinâmico dos sistemas em superfície e a região de atuação do ar frio. Em 2012, notava-se uma atuação transversal do cavado em médios níveis, que estava orientado de noroeste-sudeste, desde D-3 até D-1 (Figuras 8A, 8B e 8C), porém havia orientação meridional ao sul, o que se verifica na Figura $8 \mathrm{C}$ até a isolinha de EC de 5340 mgp, entre o sul do Atlântico e o Rio Grande do Sul; esta foi justamente a região onde houve a atuação mais intensa da OF. Houve enfraquecimento do cavado em médios níveis de D0 a D+2 (Figuras 8D, 8E e 8F). Em 1994, observava-se um padrão de onda muito pronunciado de D-3 até D+1, com crista no Pacífico e cavado na América do Sul e Atlântico. Em D-2, percebe-se uma amplificação deste padrão, com o cavado orientado meridionalmente sobre a América do Sul e atingindo até o Mato Grosso do Sul, e em D-1 São Paulo (Figuras 7B e 7C). É observado o JPN acompanhando a isolinha de EC de 5460 mgp, que passa pelo sudoeste de São Paulo em D-1. 
Temperatura $2 \mathrm{~m}$ (cores, ${ }^{\circ} \mathrm{C}$, linha branca $=0^{\circ} \mathrm{C}$ ) e Temperatura $850 \mathrm{hpa}$ (linhas pretas, ${ }^{\circ} \mathrm{C}$ )

D-3 24/06/94 12z

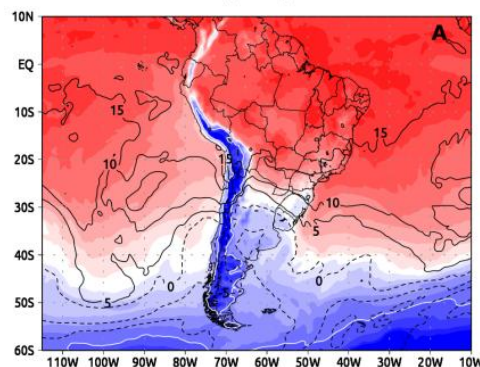

D0 $27 / 06 / 9412 z$

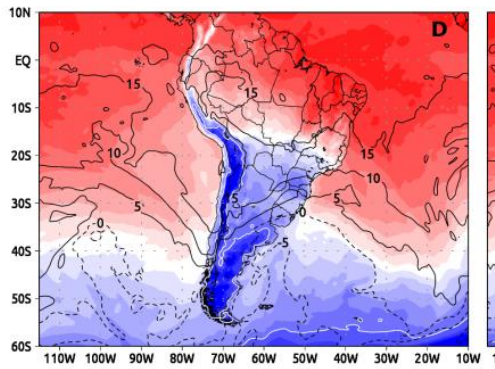

D-2 25/06/94 $12 z$

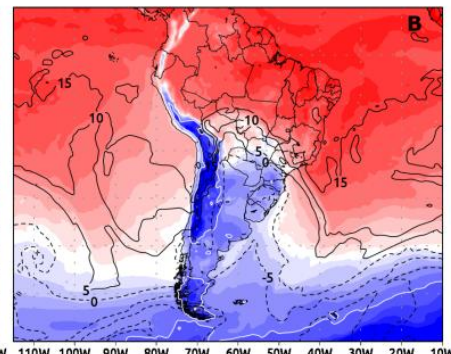

D+1 28/06/94 $12 z$

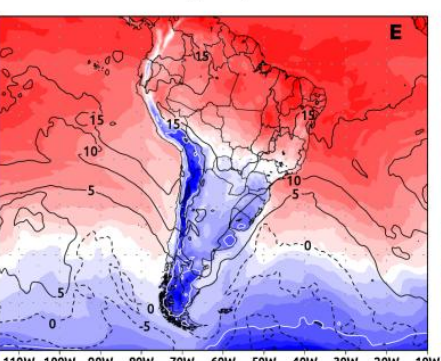

D-1 26/06/94 12z

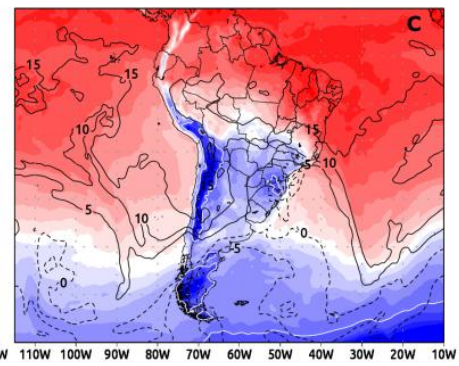

$D+2 \quad 29 / 06 / 9412 z$

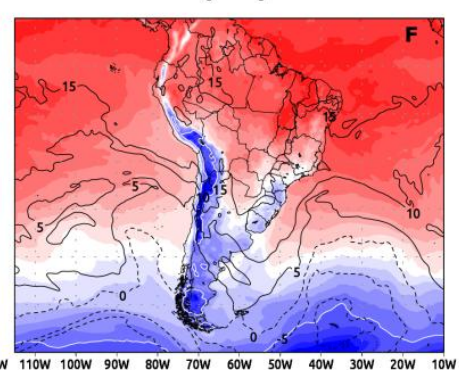

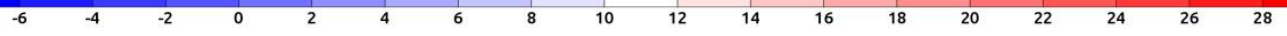

Figura 9 -T2M e T850 de D-3 a D+2 da OF ocorrida entre 25 e 29 de junho de 1994.

Temperatura $2 \mathrm{~m}$ (cores, ${ }^{\circ} \mathrm{C}$, linha branca $=0^{\circ} \mathrm{C}$ ) e Temperatura 850 hpa (linhas pretas, ${ }^{\circ} \mathrm{C}$ )

D-3 05/06/12 12z

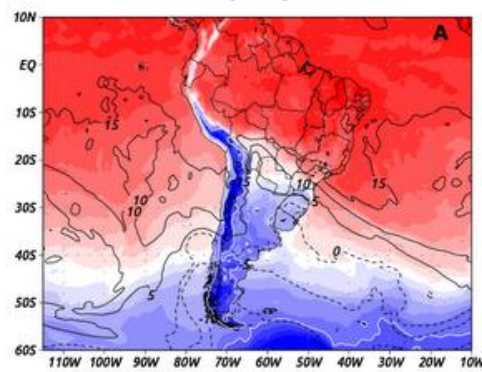

D0 $08 / 06 / 1212 z$

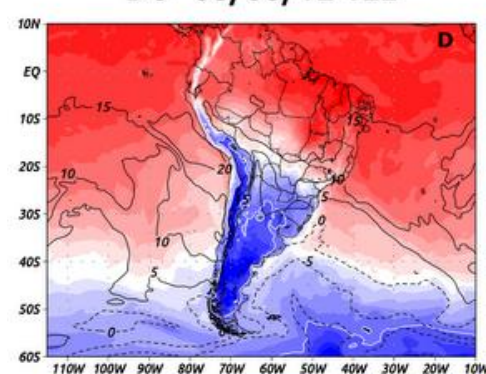

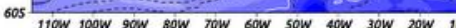

D-2 06/06/12 $12 z$

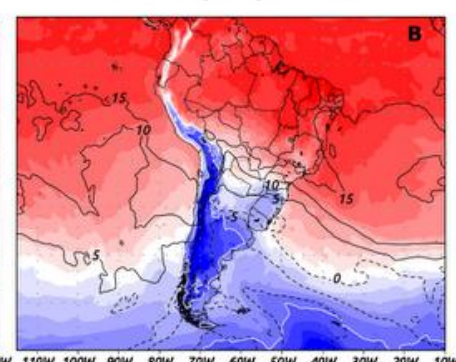

$D+1 \quad 09 / 06 / 1212 z$

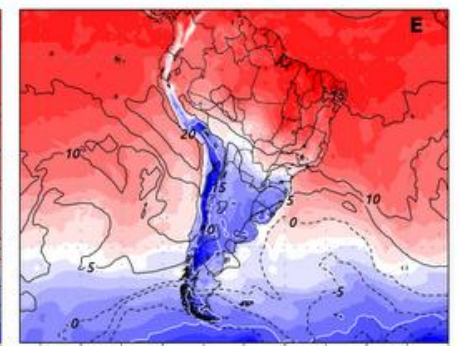

D-1 07/06/12 12z

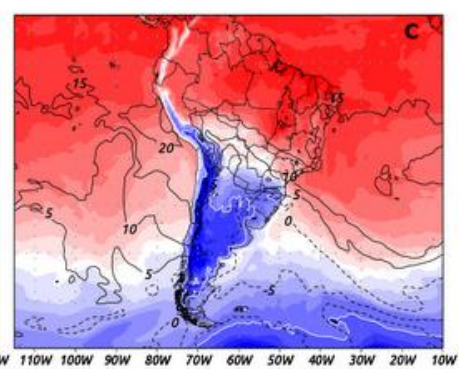

$D+2 \quad 10 / 06 / 1212 z$

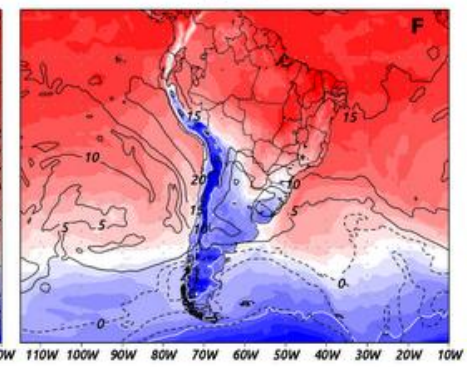

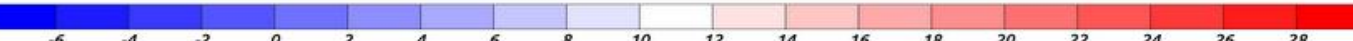

Figura 10 - T2M e T850 de D-3 a D+2 da OF ocorrida entre 5 e 10 de junho de 2012. 


\section{CONCLUSÃO}

O estudo teve como objetivo apresentar uma metodologia simples para a identificação de OF intensas na região nordeste do Estado de São Paulo no período de 1961 a 2017 e, com os casos identificados, realizar uma análise de composição para descrever as características sinóticas médias dos sistemas, desde a superfície até altos níveis, e possíveis acoplamentos entre esses níveis. Após análise dos dados e aplicação da metodologia descrita, foram identificados 12 casos de OF intensas com tempo de vida médio de 5 dias. Foi observado em superfície que a circulação do ASPS e de um sistema de baixa pressão no Atlântico, quase na mesma latitude (em torno de $35-40^{\circ} \mathrm{S}$ ), formam um corredor que permite a advecção do ar muito frio das latitudes mais altas para o continente sul-americano, e que o ASPS ao longo da costa do Chile tenta transpor os Andes numa região com menores altitudes dando origem a outro anticiclone migratório com trajetória para norte/nordeste sobre a Argentina e Paraguai; este anticiclone usualmente acompanha a movimentação da baixa no Atlântico mencionada anteriormente no mesmo sentido de deslocamento. De dois a três dias após esta transposição, o anticiclone migratório fica mais intenso devido ao suporte dinâmico de sistemas que atuam em níveis superiores, e se estabelece no dia pico sobre o Mato Grosso do Sul, Paraná e São Paulo.

Esses sistemas, em geral, apresentam um padrão de onda, com crista no Pacífico sobre o ASPS, e cavado no Atlântico sobre a América do Sul, orientados meridionalmente. Tal orientação permite a incursão de ar polar em latitudes mais baixas, propiciando a ocorrência de OF tanto no sudeste quanto no centrooeste do Brasil. O ar frio trazido pela combinação destes fatores, que em geral é bastante seco (pouca disponibilidade de vapor d'água em toda a coluna atmosférica), aliado à estabilidade causada pelo estabelecimento do anticiclone migratório na região de estudo (pouco vento próximo ao núcleo de alta pressão), propicia a ocorrência de geadas que, muitas vezes, são prejudiciais a diversas culturas, como café, milho, trigo, hortaliças, frutas tropicais, entre outras. Girardi (1983) se empenhou na tentativa de prever as OF potencialmente prejudiciais à agricultura tropical e subtropical pela observação de regiões escuras com formato arredondado em imagens de satélite na costa do Chile, ao qual nomeou de "Poço dos Andes", que era, segundo o autor, prenúncio de grande resfriamento no sul e sudeste do Brasil nos 3 ou 4 dias seguintes. Hoje, com recursos mais avançados, comprovam-se as observações de Girardi, pois o semicírculo negro observado é devido ao movimento subsidente do ASPS poucos dias antes de uma OF ocorrer. O estabelecimento de um padrão sinótico desse tipo de evento é de vital importância para se observar semelhanças nos prognósticos a fim de se prevenir ou minimizar perdas na agricultura, e também para tornar mais eficazes os alertas e minimizar os impactos sociais das ondas de frio, em especial as pessoas em situação de rua.

\section{AGRADECIMENTOS}

Os autores agradecem a Murilo Ruv Lemes, por ter confeccionado a Figura 1, a Ricardo Aguilera, Angélica Prela e Denise Masieiro, do Instituto Agronômico de Campinas (IAC) por disponibilizarem dados indispensáveis para o estudo, a Gabriel Blain, pelo apoio e dados, a Rafael Perussi, da Escola de Engenharia de São Carlos (EESC/USP) por ter cedido dados da estação 
climatológica, e ao Instituto Nacional de Meteorologia (INMET). A segunda autora também agradece o apoio do CNPq e FAPEMIG.

\section{REFERÊNCIAS BIBLIOGRÁFICAS}

ALVES, M. P. A.; SILVEIRA, R. B.; BITENCOURT, D. P.; FRANKE, A. E. Onda de frio? Análise de diferentes métodos de identificação. Revista Brasileira de Climatologia, ano 13, v. 21, p. 295-312, 2017.

BOOTSMA, A. Frost risk survey of Prince Edward Island. Ottawa: Department of Agriculture and Forestry, Canadá, 1980. 35p.

CAFEICULTOR deve se capitalizar para enfrentar produção menor. O Estado de São Paulo, São Paulo, 27 jul. 1994. Agrícola, p. G10.

CAMARGO, A. P. Geada, o "remédio" é prevenir. Boletim Técnico CATI, (227). Governo de São Paulo, 10 p., 1997.

CAMARGO, M. B. P.; PEDRO JÚNIOR., M. J.; ALFONSI, R. R.; ORTOLANI, A. A. Probabilidade de ocorrência de temperaturas mínimas absolutas mensais e anuais no Estado de São Paulo. Bragantia, Campinas, v. 52, n. 2, p. 161-168, 1993.

CAPUCIN, B. C.; LLOPART, M.; REBOITA, M. S.; IWABE, C. M. N. Análise Sinótica de um Período Frio em Bauru-SP em Julho de 2015. Anuário do Instituto de Geociências - UFRJ, v. 42, n. 1, p. 53-65, 2019.

CULTURAS de SP também sofrem prejuízos. O Estado de São Paulo, São Paulo, 16 ago. 1978 . p. 38.

CUNHA, L.; LEAL, C. Ondas de calor e ondas de frio no município de Torres Novas. Cadernos de Geografia, n.32, p. 81-93, 2013.

ESCOBAR, G. C. J. Padrões sinóticos associados a ondas de frio na cidade de São Paulo. Revista Brasileira de Meteorologia, v. 22, n. 2, p. 241-254, 2007.

ESCOBAR, G. C. J.; COMPAGNUCCI, R.; BISCHOFF, S. Sequence patterns of $1000 \mathrm{hPa}$ and $500 \mathrm{hPa}$ geopotential height fields associated with cold surges over Central Argentina. Atmosfera, v. 17, n. 2, p. 69-89, 2004.

ESCOBAR, G. C. J.; VAZ, J. C. M.; REBOITA, M. S. Circulação Atmosférica em Superfície Associada às Friagens no Centro-Oeste do Brasil. Anuário do Instituto de Geociências - UFRJ, v. 42, n. 1, p. 241-254, 2019.

ESPINOZA, J. C.; RONCHAIL, J.; LENGAIGNE, M.; QUISPE, N.; SILVA, Y.; BETTOLLI, M. L.; AVALOS, G.; LLACZA, A. Revisiting wintertime cold air intrusions at the east of the Andes: propagating features from subtropical Argentina to Peruvian Amazon and relationship with large-scale circulation patterns. Climate dynamics, v. 41, n. 7-8, p. 1983-2002, 2012.

FIRPO, M.A.F.; SANSIGOLO, C.A.; de ASSIS, S.V. Climatologia e variabilidade sazonal do número de ondas de calor e de frio no Rio Grande do Sul associadas ao ENOS. Revista Brasileira de Meteorologia, v.27, p. 95-106, 2012.

FORTUNE, M. A.; KOUSKY, V. E. Two severe freezes in Brazil: precursors and synoptic evolution. Monthly weather review, v. 111, n. 1, p. 181-196, 1983.

FRIO aumenta e a neve cai em cidades do Sul. O Estado de São Paulo, São Paulo, 08 ago. 1987. p. 14. 
GARREAUD, R. D.; ACEITUNO, P. Atmospheric circulation over South America: mean features and variability. In: The physical geography of South America. Oxford: Oxford University Press, cap. 2, 2001.

GARREAUD, R. D. Cold Air Incursions over Subtropical South America: Mean Structure and Dynamics. Monthly Weather Review, v. 128, n. 7, p. 2544-2559, 2000.

GEADA afeta cafezais e pastagem de Franca e Sudeste de Minas. O Estado de São Paulo, São Paulo, 09 ago. 1987. p. 38.

GEADA afeta fruta tropical. O Estado de São Paulo, São Paulo, 13 jul. 1994. Agrícola, p. G20.

GEADA pode reduzir de $20 \%$ safra de café. O Estado de São Paulo, São Paulo, 16 ago. 1978. p. 38.

GEIGER, R. The climate near the ground. Cambridge: Harvard University Press, 1965. $611 \mathrm{p}$.

GIRARDI, C. O Poço dos Andes. Relatório Técnico ECA 01/83, Centro Técnico Aeroespacial, 1983.

GLICKMAN, T. S. Glossary of Meteorology. American Meteorological Society, 2000.

HAMILTON, M. G.; TARIFA, J. R.; Synoptic aspects of a polar outbreak leading to frost in tropical Brazil, July 1972. Monthly Weather Review, v. 106, p. 1545$1556,1978$.

IPCC, 2013. Climate change 2013: The physical science basis. Contribution of Working Group I to the Fifth Assessment Report of the Intergovernmental Panel on Climate Change (T. F. Stocker, D. Qin, G.-K. Plattner, M. Tignor, S. K. Allen, J. Boschung, A. Nauels, Y. Xia, V. Bex and P. M. Midgley, Eds.). Cambridge University Press, Cambridge, United Kingdom and New York, NY, USA, 1535 pp.

KRISHNAMURTI, T. N.; TEWARI, M.; CHAKRABORTY, D. R.; MARENGO, J.; DIAS, P. L. S.; SATYAMURTY, P. Downstream amplification: a possible precursor to major freeze events over Southeastern Brazil. Weather and Forecasting, v. 14, n. 2, p. 242-270, 1999.

LACATIVA, A. Z. Geadas em regiões tropicais - uma resenha bibliográfica. Boletim de Geografia, Universidade Estadual de Maringá (UEM), ano 3, n. 3, p. 69-83, 1985.

LANDA, A. L. G. Olas de frío en la zona central del Estado de Veracruz. Facultad de Instrumentación Electrónica y Ciencias Atmosféricas. Universidad Veracruzana. 49 p., 2012.

LANFREDI, I. S.; DE CAMARGO, R. Classification of Extreme Cold Incursions over South America. Weather and Forecasting, v. 33, n. 5, p. 1183-1203, 2018.

LUPO, A. R.; NOCERA, J. J.; BOSART, L. F.; HOFFMAN, E. G.; KNIGHT, D. G. South American cold surges: types, composites and case studies. Monthly Weather Review, v. 129, n. 5, p. 1021-1041, 2001.

MARENGO, J. A.; AMBRIZZI, T.; KILADIS, G.; LIEBMANN, B. Upper-air wave trains over Pacific Ocean and wintertime cold surges in tropical-subtropical South America leading to Freezes in Southern and Southeastern Brazil. Theoretical and Applied Climatology, v. 73, n. 3-4, p. 223-242, 2002. 
MARENGO, J. A.; CORNEJO, A.; SATYAMURTY, P.; NOBRE, C.; SEA, W. Cold surges in tropical and extratropical South America: the strong evento in june 1994. Monthly Weather Review, v. 125, n. 11, p. 2759-2786, 1997.

MATEUS, C. Ondas de calor e ondas de frio em Coimbra: impactes na mortalidade da população. Dissertação de mestrado em Geografia Física, Universidade de Coimbra, 112 p., 2014.

MENDONÇA, M.; ROMERO, H. Ondas de frio, índices de oscilação e impactos socioambientais das variabilidades climáticas de baixa frequência na América do Sul. Acta Geográfica, p. 185-203, 2012.

METEOROLOGIA prevê nova geada. O Estado de São Paulo, São Paulo, 11 jun. 1985. p. 14.

MONTEIRO, C. A. F. Calamidades Meteorológicas no Brasil Meridional, em Agôsto de 1965. Revista Geográfica, v. 35, n. 63, p. 173-178, 1965.

MÜLLER, G. V.; GAN, M. A.; DAL PIVA, E.; SILVEIRA, V. P. Energetics of wave propagation leading to cold event in tropical latitudes of South America. Climate Dynamics, v. 45, n. 1-2, p. 1-20, 2015.

NAIRN, J.; FAWCETT, R. Defining heatwaves: heatwave defined as a heatimpact event servicing all community and business sectors in Australia. CAWCR Technical Report, n. 060, 2013.

O FRIO começa a afetar a agricultura. O Estado de São Paulo, São Paulo, 07 jun. 1988. p. 36.

PARMENTER, F. C. A Southern Hemisphere cold front passage at the equator. Bulletin of the American Meteorological Society, v. 57, n. 12, p. 1435-1440, 1976.

PEZZA, A. B. Ondas de frio na América do Sul e as trajetórias dos ciclones e anticiclones extratropicais: climatologia sinótica. Tese de Doutorado. Departamento de Ciências Atmosféricas, Instituto de Astronomia, Geofísica e Ciências Atmosféricas. São Paulo, 2003.

PEZZA, A. B.; AMBRIZZI, T. Dynamic conditions and synoptic tracks associated with diferente types of cold surge over tropical South America. International journal of climatology, v. 25, n. 2, p. 215-241, 2005.

PEZZI, L. P.; ROSA, M. B.; BATISTA, N. N. M. A Corrente de Jato sobre a América do Sul. In: Boletim Climanálise. CPTEC - Centro de Previsão de Tempo e Estudos Climáticos, Cachoeira Paulista-SP, 1996.

PINTO, H. S.; ALFONSI, R. R. \& PEDRO JR., M. J. Estimativa de danos em cafezais por geada. In: CONGRESSO BRASILEIRO DE PESQUISAS CAFEEIRAS, 4., Caxambu, 1976. Resumos. Caxambu, Instituto Brasileiro do Café, 1976. p.25-26.

PINTO, H. S.; CAMARGO, M. B. P.; NOBREGA, M.; ORTOLANI, A. A. Um sistema computacional para levantamento de prejuízos causados por geadas à cafeicultura do Estado de São Paulo. In: CONGRESSO BRASILEIRO DE PESQUISAS CAFEEIRAS 6., 1978, Ribeirão Preto. Resumos Expandidos. Ribeirão Preto: IBC-GERCA, 1978. p.145-147.

POLI, P.; HERSBACH H.; DEE, D. P. ERA-20C: An atmospheric reanalysis of the twentieth century. Journal of Climate, v. 29, n. 11, p. 4083-4097, 2016 
REBOITA, M. S.; KRUCHE, N. Normais Climatológicas Provisórias de 1991 a 2010 para Rio Grande, RS. Revista Brasileira de Meteorologia, v. 33, n. 1, p. 165-179, 2018.

REBOITA, M. S.; ESCOBAR, G.; LOPES, V. Climatologia sinótica de eventos de ondas de frio sobre a região sul de Minas Gerais. Revista Brasileira de Climatologia, ano 11, v. 16, p. 72-92, 2015.

RICARTE, R. M. D.; HERDIES, D. L.; BARBOSA, T. F. Patterns of atmospheric circulation associated with cold outbreaks in Southern Amazonia. Meteorological Applications, v. 22, n. 2, p. 129-140, 2015.

SARTORI, M. G. B. A dinâmica do clima do Rio Grande do Sul: indução empírica e conhecimento científico. Terra Livre, v. 1, n. 20, p. 27-50,2003

SENTELHAS, P. C.; ORTOLANI, A. A.; PEZZOPANE, J. R. Estimativa da temperatura mínima de relva e da diferença de temperatura entre o abrigo e a relva em noites de geada. Bragantia, v. 54, n. 2, p. 437-445, 1995.

SILVEIRA, R.D. Risco climático e vulnerabilidade socioespacial: o exemplo dos eventos extremos relacionados ao calor e ao frio. Revista Brasileira de Climatologia, v.19, p. 36-53, 2016.

TITARELLI, A. H. A onda de frio de abril de 1971 e sua repercussão no espaço geográfico brasileiro. Universidade de São Paulo, Instituto de Geografia, 1972.

TRIOLA, M. F. Introdução à estatística. 12 ed. São Paulo: LTC, 2017. 836 p.

VAVRUS, S.; WALSH, J.E.; CHAPMAN, W.L.; PORTIS, D. The behavior of extreme cold air outbreaks under greenhouse warming. International Journal of Climatology, n. 26, p. 1133-1147, 2006.

VERA, C. S.; VIGLIAROLO, P. K.; BERBERY, E. H. Cold season synoptic-scale waves oves subtropical South America. Monthly Weather Review, v. 130, n. 3, p. 684-699, 2002.

WMO. Guidelines of the definition and monitoring of extreme weather and climate 2016.2 Disponível em: <https://www.wmo.int/pages/prog/wcp/ccl/opace/opace2/documents/Draftversi onoftheGuidelinesontheDefinitionandMonitoringofExtremeWeatherandClimateEve nts.pdf >. Acesso em 20 fev. 2019.

YAGÜE, C.; MARTIJA, M.; TORRES, J.; MALDONADO, A.; ZURITA, E. Análisis estadístico de las olas de calor y frío en España. In: XXIX Jornadas científicas de la AME. Aplicaciones Meteorológicas, 6 p. ISBN-13:979-84-611-1490-0, 2006.

YNOUE, R. Y.; REBOITA, M. S.; AMBRIZZI, T.; SILVA, G. A. Meteorologia: noções básicas. São Paulo: Oficina de Textos, 2017. 184 p. 